\title{
Challenges in Ceramic Science: A Report from the Workshop on Emerging Research Areas in Ceramic Science
}

Gregory S. Rohrer, ${ }^{\mathrm{a} \dagger}$ Mario Affatigato, ${ }^{\mathrm{b}}$ Monika Backhaus, ${ }^{\mathrm{c}}$ Rajendra K. Bordia, ${ }^{\mathrm{d}}$ Helen M. Chan, ${ }^{\mathrm{e}}$ Stefano Curtarolo, ${ }^{f}$ Alex Demkov, ${ }^{\mathrm{g}}$ James N. Eckstein, ${ }^{\mathrm{h}}$ Katherine T. Faber, ${ }^{\mathrm{i}}$ Javier E. Garay, ${ }^{\mathrm{j}}$ Yury Gogotsi, ${ }^{\mathrm{k}}$ Liping Huang, ${ }^{1}$ Linda E. Jones, ${ }^{\mathrm{m}}$ Sergei V. Kalinin, ${ }^{\mathrm{n}}$ Robert J. Lad, ${ }^{\mathrm{o}}$ Carlos G. Levi, ${ }^{\mathrm{p}}$ Jeremy Levy, ${ }^{\mathrm{q}}$ Jon-Paul Maria, ${ }^{\mathrm{r}}$ Louis Mattos Jr., ${ }^{\mathrm{s}}$ Alexandra Navrotsky, ${ }^{\mathrm{t}}$ Nina Orlovskaya, ${ }^{\mathrm{u}}$ Carlo Pantano, ${ }^{\mathrm{v}}$ Jonathan F. Stebbins, ${ }^{\mathrm{w}}$ T. S. Sudarshan, ${ }^{\mathrm{x}}$ Toshihiko Tani, ${ }^{\mathrm{y}, \mathrm{z}}$ and K. Scott Weil ${ }^{\text {aa }}$ ${ }^{\mathrm{a}}$ Department of Materials Science and Engineering, Carnegie Mellon University, Pittsburgh 15213, Pennsylvania ${ }^{\mathrm{b}}$ Department of Physics, Coe College, Cedar Rapids 52402, Iowa ${ }^{\mathrm{c}}$ Corning Incorporated, Corning 14831, New York ${ }^{\mathrm{d} D e p a r t m e n t ~ o f ~ M a t e r i a l s ~ S c i e n c e ~ a n d ~ E n g i n e e r i n g, ~ U n i v e r s i t y ~ o f ~ W a s h i n g t o n, ~ S e a t t l e, ~ 98195, ~ W a s h i n g t o n ~}$ ${ }^{\mathrm{e}}$ Department of Materials Science and Engineering, Lehigh University, Bethlehem 18015, Pennsylvania ${ }^{\mathrm{f}}$ Department of Mechanical Engineering, Duke University, Durham 27708, North Carolina ${ }^{g}$ Department of Physics, The University of Texas at Austin, Austin 78712, Texas ${ }^{\mathrm{h}}$ Department of Physics, University of Illinois, Urbana 61801, Illinois ${ }^{\mathrm{i}}$ Department of Materials Science and Engineering, Northwestern University, Evanston 60208, Illinois ${ }^{\mathrm{j}}$ Department of Mechanical Engineering, University of California at Riverside, Riverside 92521, California

${ }^{\mathrm{k}}$ Department of Materials Science and Engineering, Drexel University, Philadelphia 19104, Pennsylvania ${ }^{1}$ Department of Materials Science and Engineering, Rensselaer Polytechnic Institute, Troy 12180, New York ${ }^{\mathrm{m}}$ Inamori School of Engineering, Alfred University, Alfred 14802, New York ${ }^{\mathrm{n}}$ Oak Ridge National Laboratory, M.S. 8610, Oak Ridge 37831, Tennessee

${ }^{\circ}$ Department of Physics, University of Maine, Orono 04469, Maine ${ }^{\mathrm{p}}$ Department of Materials Science and Engineering, University of California at Santa Barbara, Santa Barbara 93106, California ${ }^{\mathrm{q}}$ Department of Physics and Astronomy, University of Pittsburgh, Pittsburgh 15260, Pennsylvania ${ }^{\mathrm{r}}$ Department of Materials Science and Engineering, North Carolina State University, Raleigh 27695, North Carolina ${ }^{\text {s}}$ The Coca-Cola Company, Atlanta 30301, Georgia ${ }^{\mathrm{t}}$ University of California Davis, Davis 95616, California

D. J. Green - contributing editor

Manuscript No. 31683. Received July 01, 2012; approved September 11, 2012.

†Author to whom correspondence should be addressed. e-mail: gr20@andrew.cmu.edu

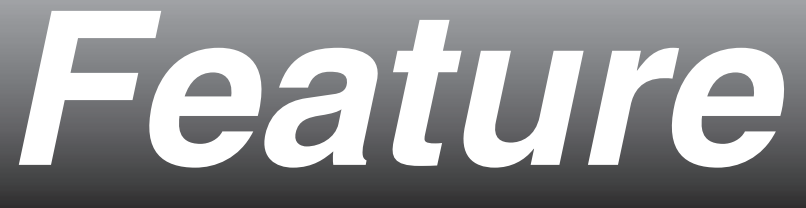


${ }^{\text {u} D e p a r t m e n t ~ o f ~ M e c h a n i c a l, ~ M a t e r i a l s ~ a n d ~ A e r o s p a c e ~ E n g i n e e r i n g, ~ U n i v e r s i t y ~ o f ~ C e n t r a l ~ F l o r i d a, ~ O r l a n d o ~ 32816, ~ F l o r i d a ~}$

${ }^{v}$ Department of Materials Science and Engineering, Pennsylvania State University, University Park 16802, Pennsylvania

${ }^{\mathrm{w}}$ Department of Geological \& Environmental Sciences, Stanford University, Stanford 94305, California

${ }^{\mathrm{x}}$ Materials Modification, Inc., Fairfax 22031, Virginia

${ }^{\mathrm{y}}$ Toyota Central Research \& Development Labs., Inc., Nagakute 480-1192, Aichi, Japan

${ }^{\mathrm{z}}$ Toyota Technological Institute, Tempaku-Ku, Nagoya 468-8511, Aichi, Japan

${ }^{a}$ Pacific Northwest National Laboratory, Richland 99352, Washington

In March 2012, a group of researchers met to discuss emerging topics in ceramic science and to identify grand challenges in the field. By the end of the workshop, the group reached a consensus on eight challenges for the future:- understanding rare events in ceramic microstructures, understanding the phase-like behavior of interfaces, predicting and controlling heterogeneous microstructures with unprecedented functionalities, controlling the properties of oxide electronics, understanding defects in the vicinity of interfaces, controlling ceramics far from equilibrium, accelerating the development of new ceramic materials, and harnessing order within disorder in glasses. This paper reports the outcomes of the workshop and provides descriptions of these challenges.

\section{Introduction}

$\mathrm{T}$ HE purpose of this paper is to report on the findings of a workshop on emerging areas in ceramic science that was held in March 2012. The workshop participants (the coauthors of this paper) represent a cross-section of the ceramics research community. At the workshop, we considered separately oxide ceramics, composites, glasses, and other nonoxide and carbon-based ceramic materials. The central goal of the meeting was to identify and articulate a set of scientific grand challenges for the ceramics research community. The challenges are of a scope that will require $5-10$ yr of effort by multiple research groups to be adequately addressed; the research conducted in response to the challenges will have significant impact on ceramic science and the broader materials science community. The challenges described in this paper are the consensus of the group and meet the criteria, but we do not claim that they are exhaustive.

The main motivation for convening this workshop is that scientific challenges in the ceramics community have not been considered in a collective or formal way for $15 \mathrm{yr}$. $^{1}$ There have been forward-looking sessions at the biannual International Congress on Ceramics, but these have had a distinct technology, rather than science, focus. ${ }^{2}$ In the $15 \mathrm{yr}$ since the last workshop on future directions for ceramics, 1 there have been some truly transformational changes in our field. In the area of characterization, atomic force microscopy, aberration-corrected transmission electron microscopy (TEM), high-speed electron backscatter diffraction mapping, three-dimensional (3-D) atom probe microscopy, and dual-beam focused ion beam scanning electron microscopy (FIB-SEM) have made the transition from curiosities to nearly standard methods enabling new discoveries. $^{3}$ In the area of synthesis and processing, thin film growth by pulsed laser deposition and molecular beam epitaxy, ${ }^{4}$ currentactivated pressure-assisted densification (CAPAD), ${ }^{5}$ and templated grain growth ${ }^{6,7}$ have all emerged as important methods for controlling the structure and composition of ceramics. There are also a range of new phenomena that have been identified and exploited in ceramics, including colossal magneto resistance, ${ }^{8}$ two-dimensional (2-D) electron gasses, ${ }^{9}$ and interface complexions, ${ }^{10}$ to name a few. Consideration of nanoceramics and nanoscale phenomena, just emerging $15 \mathrm{yr}$ ago, now permeates the field. Finally, the ability to simulate ceramics, from electronic structure calculations, ${ }^{11,12}$ kinetic Monte Carlo simulations, ${ }^{13}$ mesoscale simulations, ${ }^{14}$ and finite element models ${ }^{15}$ have kept pace with Moore's law and now permit the exploration of more practical length and time scales. In other words, the landscape for ceramics research has changed dramatically in the past $15 \mathrm{yr}$, and this is an appropriate time to consider challenges for the future.

There are other broad trends in materials research, and any consideration of the future would be incomplete without recognizing the potential influence of these factors on ceramic science. For example, issues of sustainability have to be considered. These include the embodied energy in a material, the availability of raw materials, and the ultimate disposal and/or recycling of the material. The National Academy's report on Integrated Computational Materials Engineering ${ }^{16}$ is beginning to influence the field and has led to the even more visionary Materials Genome Initiative, ${ }^{17}$ whose goal is to develop and deploy materials twice as fast and at half the cost. Each of the challenges identified by the workshop refers to opportunities created by computational capabilities and the interaction between computation and experiment, so there is considerable synergy between the eight challenges and these broader national initiatives.

The process for developing consensus on the grand challenges started before the workshop was convened. First, the group exchanged ideas about scientific challenges using an interactive web site. During the meeting, presentations describing challenges were given and discussed in panel sessions and breakout groups. By the end of the meeting, the group refined its ideas and listed eight grand challenges. The challenges are:

1. Understanding rare events in ceramic microstructures

2. Understanding the phase-like behavior of interfaces

3. Predicting and controlling heterogeneous microstructures with unprecedented functionalities

4. Controlling the properties of oxide electronics

5. Understanding defects in the vicinity of interfaces

6. Controlling ceramics far from equilibrium

7. Accelerating the development of new ceramic materials

8. Harnessing order within disorder in glasses

Each of these challenges is described in more detail in the next section. There is no priority implied by the order, but they represent the output of the subgroups who considered composites (1-3), oxides $(4,5)$, nonoxides $(6,7)$, and glasses $(8)$.

\section{Grand Challenges for Ceramic Science}

\section{(1) Understanding Rare Events in Ceramic \\ Microstructures}

The lifetimes of ceramics in many structural and functional applications are particularly sensitive to rare (sometimes described as statistical) events. These include brittle failure during mechanical or thermal loading, pitting by corrosion, dielectric breakdown, fatigue crack initiation, and by analogy, over longer time and distance scales, earthquakes. Although statistical techniques, such as those developed by Weibull, ${ }^{18}$ satisfy the needs of design engineers, they offer 
little understanding of the underlying causes of life-limiting phenomena. Even statistical techniques that focus on the probability of rare events, such as large deviation theory, ${ }^{19}$ are heuristic and provide little insight into the underlying cause of such events.

The challenge is to understand the causes and mechanisms by which rare events lead to failure. In previous attempts to gain an understanding of these processes, experiments were often engineered to eliminate their statistical nature. In fracture experiments, for example, precracks or notches are placed in specimens to provide focus for the experiment. While affording useful information in assessing the steadystate phenomena of crack growth, these experiments mask information regarding the nucleation or initiation event. Of even greater concern from a technological perspective is that lifetime predictions based on continuum or fracture mechanics treatments for artificial cracks are not appropriate for short naturally occurring cracks. An alternative approach is to conduct in situ experiments, and perform postmortem examinations to elicit knowledge of failure origins. ${ }^{20,21}$ Although postexperiment investigations may provide some clues to sources of failure, damage may cloud accurate appraisal. A new avenue of research is thus required, not only to help elucidate fundamental mechanisms of nucleation events but also to provide grist for lifetime models that more accurately portray reality.

The timing to address such problems is particularly auspicious. First, 3-D interrogation techniques (X-rays, neutrons, FIB-SEM, atom probe, serial sectioning, and reconstruction) afford both structure and composition determination at a variety of length scales, and in some cases, probe failure events in real time. For example, the recent development of laser-assisted, 3-D atom probe microscopy (3DAP) has made it possible to make 3-D, near-atomic resolution images of reasonable volumes (containing $\sim 10^{8}$ atoms) of a wide range of materials, including alumina. $^{22}$ In fact, the capabilities for 3-D imaging by $\mathrm{TEM}^{23}$ dual-beam FIB-SEM (see Fig. 1), ${ }^{24}$ X-ray tomography, ${ }^{25}$ and diffraction contrast X-ray microscopy ${ }^{26}$ have all improved significantly. ${ }^{3}$ These can be coupled with experiments that would include elevated temperatures, corrosive environments, applied loads, electric/magnetic fields, or some combination of these. Second, synthesis and processing approaches are sufficiently sophisticated that they can be used to create novel microstructures at different length scales to test hypotheses of failure origins. New synthesis methods might make it possible to create materials with controlled distributions of abnormally large grains, highangle grain boundaries, high modulus or low modulus inclusions, cavities and microcracks. Third, multiscale simulation techniques are increasingly detailed to provide an understanding of the effect of microstructure on functionality, ${ }^{27}$ and hence, provide input into lifetime models. (a)

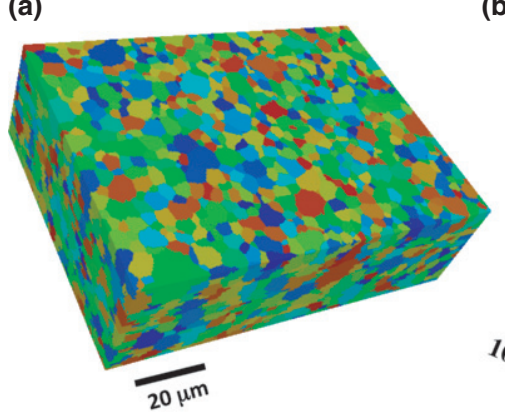

(b)

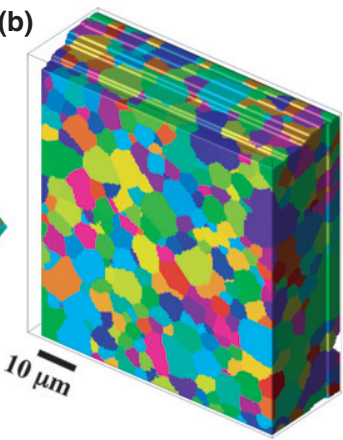

Fig. 1. (a) A three-dimensional orientation map of yttria $\left(\mathrm{Y}_{2} \mathrm{O}_{3}\right)$ based on 43 parallel EBSD maps. ${ }^{24}$ (b) A three-dimensional orientation map of $8 \%$ yttria $\left(\mathrm{Y}_{2} \mathrm{O}_{3}\right)$-stabilized zirconia $\left(\mathrm{ZrO}_{2}\right) .{ }^{152}$ Copyright John Wiley and Sons, reproduced with permission.
Understanding rare events in ceramic microstructures presents research challenges for the ceramics community, and the broader scientific community. The seemingly random nature of these events poses serious requirements for observation. First, real-time imaging is essential, providing a fourth dimension to the 3-D characterization. Such 4-D data sets will be important not only as input for phase-field or finite element codes, but for the calibration and validation and validation of these codes. Second, observation volumes must be of the order of the sample size and of the appropriate spatial resolution to "catch" the nucleation event. For example, with $\mathrm{X}$-ray imaging, large detector arrays would be required to allow sensing over the entire sampled volume in real time. Analogous screening has been done in the field of acoustics for seismic ${ }^{28}$ and biomedical imaging of random incidents ${ }^{29}$ and in structural health monitoring ${ }^{30}$ using "time-reversal imaging." The technique affords both spatial and temporal focusing on regions of interest in inhomogeneous environments. Finally, environmental control must be uniform over the entire observation volume.

Once the origins of events are established, taking advantage of additional analytical capabilities could enhance mechanistic understanding. For example, using near-field grain mapping, the evolution of the dislocation structure in individual grains could be followed, and hence, related to crack nucleation. Grain orientations could be monitored to assess corrosion prone orientations. Small-angle X-ray scattering would be useful in tracking the statistics of void formation during elevated temperature operation. ${ }^{31}$ As multiple techniques are used in concert, data (of order terabytes to petabytes) management and analysis are critical. This will require collaborations with data acquisition specialists. Real-time analysis would be particularly advantageous. Establishing the intrinsic or extrinsic causes for nucleation events based on these analyses would provide critical information for multiscale mechanistic models and life prediction strategies.

A parallel strategy should focus on the development of materials that are self-sensing and attuned to rare events, including mechano-chemically responsive materials. Sophisticated processing strategies could tailor materials to include sensing and communication functions that could couple to feedback loops that take a material/component out of service to prevent catastrophe. Self-healing concepts should also be exploited (see, for example, Hager et $a l^{32}$ ). These might involve stress-induced, corrosion-induced, or dielectric-breakdown-induced fillers. Longer term self-healing concepts might rely on analogs to biological systems.

In summary, recent advances in methods for the complete 3-D in situ characterization of structure and composition, coupled with the expanding capabilities of multiscale simulation techniques that reveal the relationship between microstructure and functionality, will bring the goal of understanding rare events within reach during the next 5-10 yr. This fundamental understanding has the potential to lead to materials that demonstrate feedback through selfsensing and self-healing functions, extending the lifetimes of materials.

\section{(2) Understanding the Phase-like Behavior of Interfaces}

The second grand challenge is to expand and redefine the current "boundaries" of ceramic behavior, by exploiting the interfaces within the structure. The electrical, thermal, and mechanical properties of bulk, polycrystalline materials are often influenced by the behavior at the grain boundaries. It is significant, therefore, that recent research findings have underscored fundamental deficiencies in our understanding of transport mechanisms along grain boundaries and structural and chemical transitions that can occur within grain boundaries. For example, several groups have shown that the incorporation of oversized dopant ions at alumina grain boundaries can significantly influence the high temperature 
mechanical $^{33-38}$ and transport behavior. ${ }^{39-48}$ It is generally accepted that the dopant ions segregate to the grain boundaries. ${ }^{44,45}$ However, the mechanism by which modification of the properties takes place is still a subject of debate; siteblocking and or modifications to the bonding are the most widely cited possibilities. ${ }^{46,47}$ It is telling that although alumina is one of the most widely studied ceramics, a recent review by Heuer ${ }^{48}$ on oxygen transport in alumina that was entitled "Oxygen and aluminum diffusion in $\alpha-\mathrm{Al}_{2} \mathrm{O}_{3}$ : How much do we really understand?" concluded that the answer was "not that much!" Indeed, the article goes on to suggest a number of fundamental topics that merit more scientific study. This dearth of knowledge is of particular relevance to ceramic materials because grain boundary diffusional processes are critical to the synthesis and processing of commercial ceramics. Boundary migration characteristics, which can undergo abrupt changes as a result of structural transitions at interfaces, determine microstructural evolution with regard to the degree and homogeneity of grain growth, as well as the crystallographic texture. As a materials class, ceramics are unique in terms of the breadth of the compositional and structural variations that can occur within boundaries. Moreover, the importance of point defects in controlling the grain boundary properties is much greater than for metallic solids. For example, model experimental studies have demonstrated that electric fields can significantly affect the rate of boundary migration. ${ }^{49,50}$

In a closely related topic, CAPAD has recently received widespread attention due to the attainment of high ceramic densities at reduced temperatures (relative to conventional processing). ${ }^{51-53} \mathrm{~A}$ perhaps more tantalizing advantage of this technique is that the benefits go beyond efficiency and offer a platform for producing materials that are extremely difficult, if not impossible, to produce by other methods. This factor is exemplified by the recent emergence of methods as a successful production tool for dense, large-sized, nanocrystalline ceramics. ${ }^{5}$ These large-sized nanocrystalline ceramics can offer a platform for the manipulation of length-scale-induced properties $^{54}$ and the study of grain and phase boundaries. While there are many mechanisms involved in the densification process, grain boundary diffusion and/or sliding are almost certainly influenced by electric fields and currents. The principles by which the electric field affects boundary migration and densification are an open question, highlighting the scientific community's incomplete knowledge of defect states at grain boundaries in ceramics.

Recently, techniques such as aberration-corrected TEM for Z-contrast imaging have emerged that can interrogate the atomistic structure of boundaries. ${ }^{55-57}$ Furthermore, methods have now been developed to obtain statistical distributions of grain misorientation and boundary planes for experimentally derived microstructures containing many thousands of grains. ${ }^{24,58-60}$ These new characterization methods, coupled with the evolution of powerful first-principles computational tools to simulate and model complex interfacial structures, make a compelling case for the scientific community to revisit the elucidation of boundary structures in ceramics, as well as structural and chemical transitions at boundaries.

A fascinating new development in terms of our view of boundaries is related to the discovery of multiple, distinct, thermodynamically stable states at grain boundaries, referred to as complexions, which do not exist as stand-alone materials. ${ }^{10,61,62}$ For example, Fig. 2 summarizes results from $\mathrm{Nd}$-doped alumina where grain boundaries with distinct structures and compositions have different mobilities, energies, orientation distributions, compositions, and atomic structures. As a second example of the influence on grain boundary complexions on properties, a recent study of ionic conductivity in $\mathrm{LaPO}_{4}$ ceramics indicated that ceramics with an amorphous film at the grain boundaries have better proton transport properties than similar materials without the amorphous film. ${ }^{63}$ Given the importance of boundaries in determining the overall material properties, this raises the exciting prospect of synthesizing new materials with unique combinations of properties that hitherto have not been observed. For example, in nanophase ceramics, interfaces will constitute a significant fraction of the overall structure. In principle, therefore, one could begin to colonize the "white space" in Ashby diagrams, ${ }^{64}$ which are the locations of contraindicative properties such as simultaneous high hardness and toughness, on property correlation maps.

\section{(3) Predicting and Controlling Heterogeneous Microstructures with Unprecedented Functionalities}

Among all materials classes, ceramics offer the broadest range of chemistry, bonding, and crystal structure. Multiphasic combinations of ceramics and hybrid combinations with other materials offer the potential to realize functionalities well beyond the limits of present-day materials. However, achieving unprecedented functionalities will require a fundamental understanding and control of constituent properties, interfaces, and microstructures at length scales ranging over several orders of magnitudes.

Porous and dense ceramics, ceramic composites, and ceramic coatings will play a significant role in addressing many of our most important challenges for the future, including reduction in greenhouse gas emissions, safer nuclear reactors, clean water systems, space exploration, medical implants, tissue engineering, and actuators and sensors. Progress in the comprehensive understanding of the processing-structurefunctionality of heterogeneous, composite, anisotropic, and multilayered ceramics will have significant impact. For example, it could lead to materials with ultrahigh temperature stability, high ionic conductivity at room temperature, high temperature stable and efficient thermoelectric devices and batteries that can be charged in minutes and last hours.

In recent years, significant progress has been made in simulating the effects of electronic- and micro-structure on the properties of ceramics utilizing first-principles/ab initio, molecular dynamics, phase field and continuum models. ${ }^{65}$ Fundamental scientific understanding of the complex structure-function relationship is just emerging and continued advancement will require the integration and bridging of these different approaches as well as the development of mesoscale models that can simulate heterogeneous microstructures with greater fidelity. In parallel, there has been a rapid expansion in capabilities to probe the chemical composition and microstructure, in three dimensions and at different length scales of interest, as already noted in the two previous sections. $1,3,22-26,66$

The challenge for the future is to merge this information at various length scales and to conduct such studies as a function of the fourth dimension, time ${ }^{67}$ to develop a fundamental understanding of the evolution of the microstructure and its effect on properties. The ability to incorporate temporal effects offers an opportunity to understand the mechanisms of microstructure evolution, thermal-mechanical response, electrical response, degradation, and failure. There are a number of advancements needed in this area. One is that to gain a comprehensive understanding of a mechanism, structural characterization will need to integrate multiple techniques to span several orders of magnitude of length scales. A second barrier is the need to analyze at high scanning rates large volumes of material that contain more of the features of interest (such as second phase particles, interfaces, etc.). Even defining the representative (and relevant) volume of material required to understand the origin of a given property remains a challenge. A third challenge is to develop more facile approaches to collect time-dependent information from multiple trials using both destructive and nondestructive imaging techniques. This will require statistical metrics of structures that can be compared over time. This will not be an issue with nondestructive techniques (for example, 

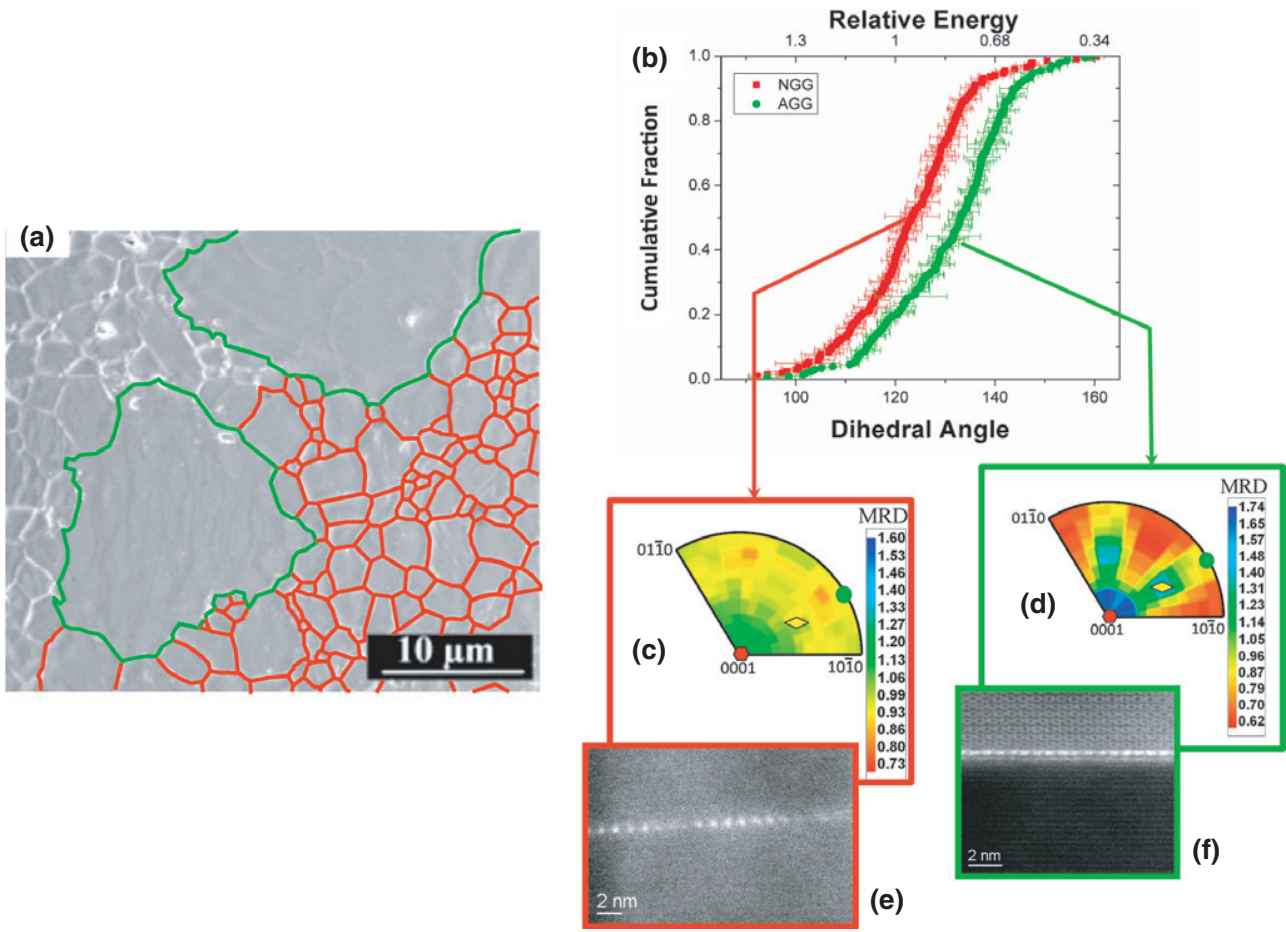

Fig. 2. The co-existence of multiple complexions in Nd-doped alumina can lead to a bi-modal grain size distribution if the mobilities of the complexions differ significantly. ${ }^{153}$ The boundaries in the SEM micrograph (a) are colored to differentiate high mobility boundaries (green) from low mobility boundaries (red). Thermal groove measurements of the grain boundary energies, colored in the same way (b), indicate that the high mobility complexion has a lower energy. ${ }^{154}$ The two complexions also have different grain boundary orientation distributions (c, d). ${ }^{61}$ HRTEM shows that the low mobility boundary has a monolayer of segregated $\mathrm{Nd}$ and the high mobility grain boundary has a bilayer of segregated Nd $(\mathrm{e}, \mathrm{f}) .{ }^{10}$ Copyright John Wiley and Sons, reproduced with permission.

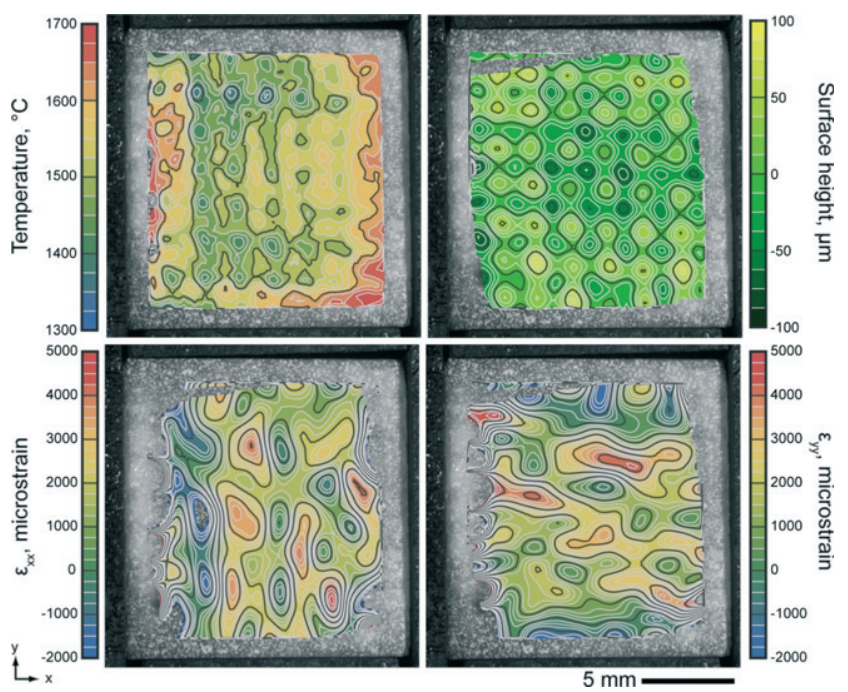

Fig. 3. Contour plots of temperature, surface height, and strain maps of a multi-ply plain-weave $\mathrm{C} / \mathrm{SiC}$ composite at $1500^{\circ} \mathrm{C}$. Reproduced from Novak and Zok. ${ }^{68}$ Copyright AIP, reproduced with permission.

those that use X-rays as a probe), but currently, nondestructive techniques do not cover all length scales. While the barriers are significant, the multiscale characterization of chemistry, microstructure, defects, interfaces, and composition as a function of time will lead to increasingly powerful structure-mechanism-property relationships for a wide range of ceramic and composite materials. Research in which advanced characterization techniques are integrated with time-dependent studies are in their early stages, but promising. For example, Fig. 3 shows a recent high temperature measurement of strain in a $\mathrm{C} / \mathrm{SiC}$ composite. ${ }^{68}$
Research needs to be conducted on developing meso-scale simulation approaches that fully account for this rich chemical and microstructural detail to predict the properties of these heterogeneous materials. In addition, theoretical, experimental, and simulation research on the accelerated testing of ceramics in aggressive environments is needed to understand the performance of ceramics in expected conditions. Such approaches are in the early stage of development. Limited work has been conducted, for example, on the sensitivity of the properties to different microstructural features. Further scientific research in this area should lead to an ability to quantitatively predict the properties of complex multiscale microstructures from a set of required microstructural features.

The third area of importance is the analysis and the simulation of the evolution of the microstructure at multiple length scales during processing. Some progress has been made in the simulation of microstructural development during sintering. ${ }^{69-72}$ In parallel, impressive progress has been made in processing ceramics with well-controlled microstructures including micro-texture..$^{6,7,73,74}$ However, much more research is needed to understand microstructural evolution during processing.

Tailored fabrication of novel ceramic materials composed of periodic arrays of micro- and nanoscale phases is still in its infancy. For example, it has been shown that chemical functionalization and bonding can be used to predictably assemble distinctly different sets of oxide nanoparticles. ${ }^{75-77}$ Approaches such as these can offer general fabrication platforms to produce dense hybrid composites with property combinations of interest in a broad range of applications including energy storage, photon harvesting, and catalysis.

The challenge is to integrate advances in the three areas (simulations, characterization, and processing) in a way that simulations can be used as a predictive tool to develop processing schemes that can generate materials with unprecedented functionality via microstructural design. On the 
experimental side, this requires novel synthesis and processing strategies for precise control of microstructures, interfaces and defect populations, and thorough quantification of microstructural evolution at different length scales (which may require development of in situ techniques). On the simulation side, it requires the integration of simulations at different length scales to develop a set of experimentally verifiable features of the evolving microstructures and the effects of the microstructural features at different length scales on properties. Ultimately, these two will be integrated to develop robust approaches that can be used to understand and control microstructural evolution in a predictive manner for complex material systems (such as multimaterial, multilayered, and porous materials). This is an inherently difficult problem and a grand challenge in our field. However, the tools are rapidly becoming available to tackle it.

\section{(4) Controlling the Properties of Oxide Electronics}

The past $15 \mathrm{yr}$ of research on oxide single crystals and thin films provides great insight into the diverse spectrum of electronic, optical, and magnetic properties of ceramic oxide materials that were historically categorized as passive insulators. For example, precise control of the $\mathrm{LaAlO}_{3} / \mathrm{SrTiO}_{3}$ interface demonstrates that the joining of two linear dielectrics can lead to a high mobility electron gas. ${ }^{78}$ This discovery of electronic ceramic functionality was enabled by a community of experimentalists and theorists who developed synthesis methods and models that begin to approach the sophistication of the materials science that governs the semiconductor industry. Another example is memristive and electroresistive electronics based on reversible formation and dissolution of conductive filaments. ${ }^{79,80}$ The future challenge is to design and synthesize oxide surfaces, interfaces, and nanoscale structures that catalyze a wide spectrum of scientifically inspiring electronic properties, including high mobility, superconductivity, and magnetism, that are tunable by external electrical, optical, magnetic, mechanical, and chemical stimuli. Crystal growth and design, the control of defects, and integration with other materials are all relevant issues associated with this challenge.

Because of their nonlinear properties, oxides have the potential to reveal phenomena not possible in conventional group IV and III-V semiconductor electronics. This is because there are distinct differences in the electronic structure, as illustrated schematically in Fig. $4 .^{76}$ For a 2-D electron gas at the $\mathrm{GaAs} / \mathrm{Al}_{\mathrm{x}} \mathrm{Ga}_{1-x} \mathrm{As}$ interface, there is a single extended quantum well at the interface. In comparison, for the $\mathrm{LaAlO}_{3} / \mathrm{SrTiO}_{3}$ interface, the ionic potential creates multiple quantum wells localizing the electrons to a few planes parallel to the interface. These localized quantum wells are strongly influenced by applied fields, leading to switching behavior, and can be patterned with nanometer scale precision. ${ }^{81}$

The exciting potential of sophisticated oxide ceramic devices is enabled by significant advances since the late 1990s in synthesis, characterization, and nanofabrication. For example, atomic force microscopes are present in virtually every shared facility, and atomic-resolution microscopy is no longer reserved to specialized institutions. Collectively, the oxide electronics community finds itself positioned to explore new properties and phenomena that originate at/from heterojunctions and hetero-interfaces. ${ }^{82}$ Current trends demonstrate that the exquisite interface functionality of compound semiconductors is also present in oxide ceramics, but will require major advances in the next decade to yield comparable material quality and precise control of defects and interfacial bonding.

The crystal chemistry of complex oxides endows them with a uniquely broad set of dielectric, optical, electrochemical, and magnetic properties. The nascent ability to prepare and integrate these materials with nanometer precision allows one to envision heterostructures that superimpose bulk and interfacial properties, leading to a new set of miniature, low cost, electronic architectures, and devices. Advances in fundamental scientific knowledge in this area will lead to major breakthroughs in next generation oxide electronics, including new technologies associated with, for example, superconducting switches, ${ }^{83}$ reconfigurable logic, ${ }^{81}$ and quantum computation. ${ }^{84}$

The promise of new functionality is created by rational interface design and precise nanostructure control, and is grounded in materials physics and chemistry. However, realizing next generation oxide electronics will require significant synergy between materials theory, modeling, synthesis, characterization, and nanomanufacturing. Major scientific advances are required, including a sophisticated ability to control stoichiometry, strain, defect chemistry, crystallinity, and diffusion at interfaces, which incorporate increasing chemical, structural, polar, and bonding contrast. By nature
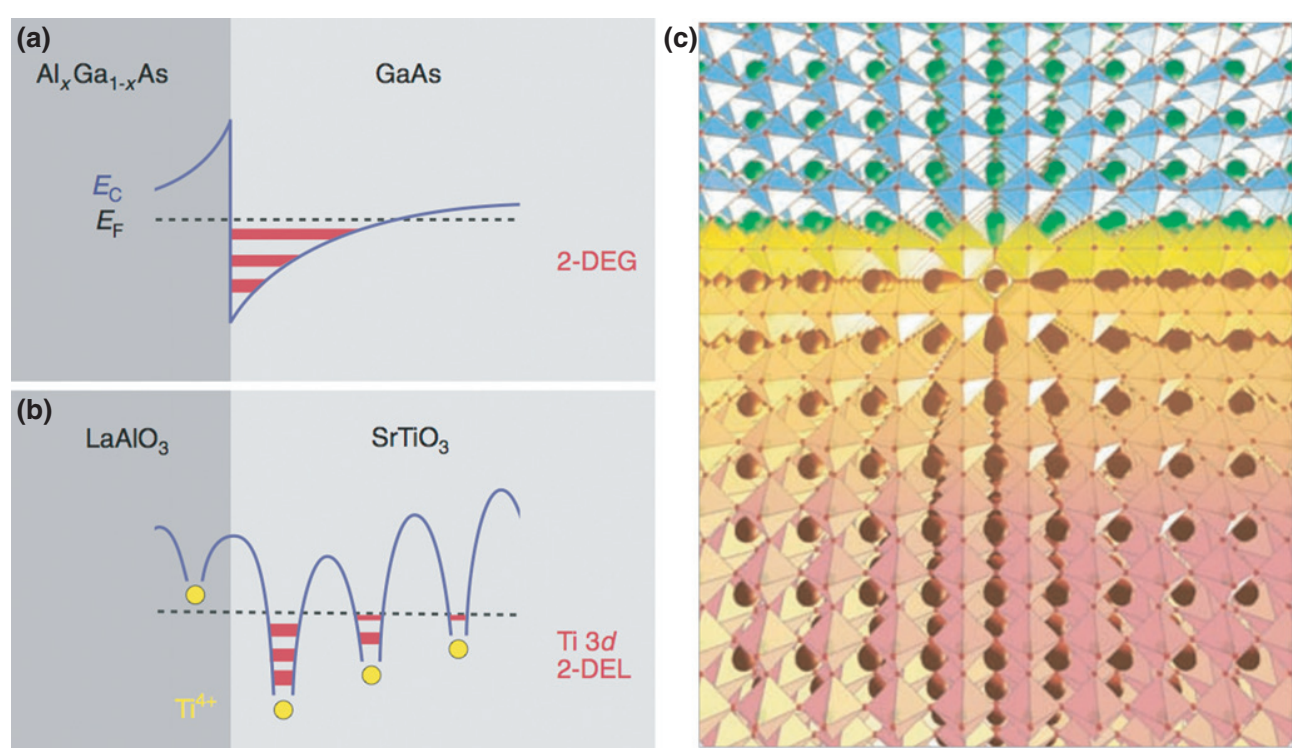

Fig. 4. Schematic energy level diagrams (a and b) illustrating the difference between electrons trapped at the (a) $\mathrm{GaAs} / \mathrm{Al}_{\mathrm{x}} \mathrm{Ga}_{1-x} \mathrm{As}$ and (b) $\mathrm{LaAlO}_{3} / \mathrm{SrTiO}_{3}$ interfaces. (c) Illustration of the $\mathrm{LaAlO}_{3} / \mathrm{SrTiO}_{3}$ interface, with $\mathrm{SrTiO}_{3}$ on the bottom. Locations of mobile electrons are indicated by increasing yellow color. Reproduced from Mannhart and Schlom. ${ }^{82}$ Copyright AAAS, reproduced with permission. 
of their complex structure and chemistry, active interfaces in oxide ceramics create a rich diversity of future technologies, but scientific advances will require comprehensive efforts that integrate theory with experiment.

\section{(5) Understanding Defects in the Vicinity of Interfaces}

Advanced materials span a continuum from passive to functional behavior. Modern technologies that address energy, sustainability, and miniaturization will require a departure from the tailoring of continuously varying properties to engineered multifunctionality. In other words, technology demands will not usually be met by single-phase materials. For example, energy storage technologies need solid electrolytes offering ten times higher ionic conductivities, ${ }^{85}$ energy harvesters need thermoelectrics that decouple phonon and electron transport, ${ }^{86}$ solid oxide fuel cells (SOFC) need to operate at significantly reduced temperatures, ${ }^{87}$ and filtration technologies need materials with graded nanoporosity, chemically active surfaces, and environmental stability. The SOFC is an example of a system in which improvements in efficiency, life times, and costs have been elusive, despite a long history of research. ${ }^{88}$ Advancements in our knowledge of the mechanisms of oxygen-solid reactions and oxygen vacancy transport across interfaces are required for knowledge-based advancements of technologies such as the SOFC.

Future materials that meet these technology needs will likely evolve from a synthetic class of nanoheterogeneous but monolithic hybrids that superimpose the functionality of multiple materials at dramatically reduced dimensions. Ceramic oxides are of particular interest to this challenge as their core electronic, chemical, and ionic properties provide a foundation for the desired performance. Furthermore, the past $15 \mathrm{yr}$ of ceramics research empowered the community with access to a diverse spectrum of particles, monoliths, and films with nanometer scale dimensions. These low-dimensional embodiments enable one to tune phase transitions, ${ }^{89}$ surface reactivities, ${ }^{90,91}$ transport, ${ }^{92}$ and other physical properties. The importance of interfaces on properties is illustrated by the results shown in Fig. 5. These data demonstrate that as the accumulation zones in $\mathrm{BaF}_{2} / \mathrm{CaF}_{2}$ heterostructures are brought closer together, the ionic conductivity increases significantly. ${ }^{93}$ The recent report of "colossal ionic conductivity" in YSZ/SrTiO 3 heterostructures supports the idea that interfaces between dissimilar materials can be

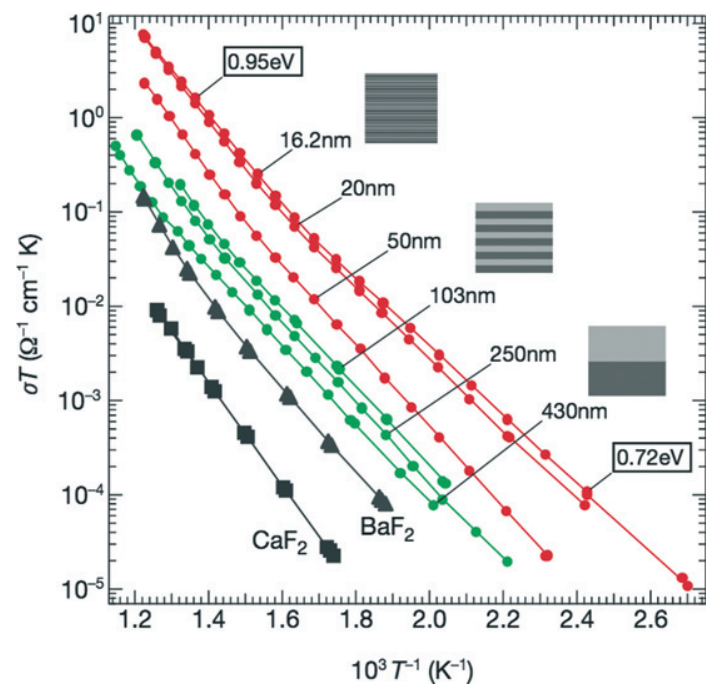

Fig. 5. Ionic conductivities of $\mathrm{CaF}_{2} / \mathrm{BaF}_{2}$ heterostructures parallel to the interface for superlattices with a range of periodicities. At a fixed temperature, the ionic conductivity increases as the period decreases. Reproduced from Sata et al. ${ }^{93}$ Copyright Nature Publishing Group, reproduced with permission. manipulated to control properties. ${ }^{94}$ Important technology needs will be met if the materials community can "integrate on-demand" while maintaining small dimensions.

The result of this integration is a class of materials where the relative fractions of interface and bulk material approach each other. Such structures are far from equilibrium, and the evolution of their defect chemistry in a highly metastable state is poorly understood. For example, recent results ${ }^{95,96}$ illustrate that reversible vacancy redistribution is possible in oxides at room temperature and below in sufficiently high electric fields. These studies complement such established areas as irreversible fatigue of ferroelectric materials. ${ }^{97}$ At the same time, there is an emerging recognition that stresses from interfaces also influence defect concentrations. ${ }^{98}$ The existing fundamental thermodynamic theory for point defects, ${ }^{99,100}$ on the other hand, explicitly ignores the interface structure and the proximity to interfaces that act as sources and sinks. Our inability to describe this situation is exacerbated by the accelerated kinetics of defect formation and transport that occurs via surfaces and interfaces and degrades stability. The challenge is to extend defect chemistry models to account for the metastability of defect distributions in nano-heterogeneous ceramic systems where surfaces and interfaces are closely spaced. Models for defect distributions in these conditions must also account for the composition of the gaseous environment, high pressure and temperature as well as high strain (often present in heterostructures) and high electric fields. To meet this challenge, a new defect chemistry perspective is needed that merges controlled atmosphere surface science (as opposed to ultrahigh vacuum) with thermodynamic and kinetic models for defect formation.

Until recently, there have been few direct measurements of surface and interface energies. However, recent calorimetric measurements on nanoparticles and dense nanoceramics are expanding the database and enabling calculations of phase stability on the nanoscale. ${ }^{89,101-103}$ Similarly, grain boundary energies derived from microstructural geometry are also becoming available. ${ }^{24,58,60,104}$ Computational efforts associated with the Materials Genome Initiative are expected to improve this situation in the future. ${ }^{17}$ The nature of defects at surfaces, interfaces, and grain boundaries is critical to oxide ceramic functionality. Metastable defect distributions that can be controlled through synthesis and processing can be used as an advantage in tailoring oxide ceramic functionality, but the thermodynamic driving forces and kinetic pathways that move the system toward true equilibrium markedly affect the long-term stability and ultimate usefulness of these materials, particularly in high-temperature and/or chemically harsh environments.

\section{(6) Control of Ceramics Far From Equilibrium}

Because of advances in processing methods during the past decade, ceramic science has been freed from the "tyranny of equilibrium," that is, one can now synthesize ceramic materials which do not represent the state of lowest free energy but which persist, sometimes to surprising high temperatures, and can be fabricated and utilized in a variety of applications. These are often nanostructured, with phase assemblages, crystallographic structures, and microstructures different from those of bulk materials. Frequently, interfaces between like or unlike particles impart additional unique properties.

It is now possible to prepare materials that have extremely high surface areas because of their internal porosity, very small particle size, or because they are comprised of quasi $1-\mathrm{D}$ (fibers) or 2-D (exfoliated layers) ${ }^{105}$ components. However, it remains a challenge to predict how the thermodynamic, physical, structural, and functional properties of materials prepared far from equilibrium differ from those of the bulk equilibrium phases, and how these properties change 
with composition and grain size. It is also necessary to understand when such materials have acceptable lifetimes in applications and when they evolve to other states which often compromise function. To reach this goal, there must be greater synergy between theory-computation-modeling and experimental measurements, with the former providing mechanistic insights at the molecular scale and identifying areas where new measurements are needed, and the latter benchmarking the accuracy of the former.

The challenge here is to understand and predict how the thermodynamic, physical, structural, and functional properties of materials prepared far from equilibrium differ from those of the bulk equilibrium phases, and how these properties change with composition and grain size. This understanding is a prerequisite to tailoring materials for specific applications and to using concepts such as "inverse design" to find optimum materials for a given application. It is also a prerequisite to understanding when such materials have acceptable lifetimes in application and when they evolve to other states which often compromise function.

As an example, recent studies have shown that, under the constraint of a given particle size, there are strong thermodynamic driving forces to favor phase assemblages of low surface or interface energies. ${ }^{89,101-103}$ For example, the prevalence of nanophase materials for new applications means that the contributions of their surfaces and interfaces to their thermodynamic properties cannot be ignored, especially in the presence of $\mathrm{H}_{2} \mathrm{O}, \mathrm{CO}_{2}$, or other adsorbed species. Recently measured surface energies of a number of oxides show that they range between 0.5 and $4 \mathrm{~J} / \mathrm{m}^{2}$ and that differences between surface energies of different phase assemblages of the same composition can be as large as $2 \mathrm{~J} / \mathrm{m}^{2}$. Therefore, surface energy can contribute up to $20-30 \mathrm{~kJ} / \mathrm{mol}$ to the difference in free energy for a reaction involving $10 \mathrm{~nm}$ particles compared to bulk, and favoring the assemblage of lower surface energy. ${ }^{89}$ The consequences include thermodynamic stabilization at the nanoscale of polymorphs metastable in the bulk (e.g., gamma alumina relative to alpha), the shift of oxyhydroxide dehydration equilibria to higher temperatures, and substantial shifts in the positions of redox equilibria (see Fig 6). Thus one needs the thermodynamics of surfaces and interfaces to understand reactions in nanophase systems at low temperatures where particles can transform but not coarsen, as well as for the eventual sintering, coarsening, and degradation of engineered nanoscale systems and devices. In the future, it is envisioned that theory-computation-modeling, informed and benchmarked by experiments, will provide mechanistic insights at the molecular scale and identify areas where new measurements are needed.

\section{(7) Accelerating the Development of New Ceramic \\ Materials}

While there exist a wide range of synthetic paths for new ceramics, we are not yet able to make new materials in a sensible and systematic fashion and to explore the physical properties of such materials with an eye to unique behavior and novel applications. The goal is to create totally new types of ceramics rather than to modify existing ones by small changes in composition or processing. This area is especially fruitful for materials containing $\mathrm{B}, \mathrm{N}, \mathrm{C}$, chalcogenides, and halides, which have not been explored as thoroughly as oxides. Addressing this challenge will require guidance from computation on both target compositions ${ }^{11,12,106}$ and synthesis strategies as well as a merging of the practices of the synthetic chemist and ceramist.

Materials can have complex nanostructures. Examples include new borides, nitrides, and other materials prepared by chemical synthesis, 1-D and 2-D materials formed of primarily carbon, various delaminated sheets of oxides and nonoxide ceramics, dense ceramics with nanosized grains prepared by CAPAD, polymer-derived ceramics in the $\mathrm{Si}-\mathrm{C}-\mathrm{O}, \mathrm{Si}-\mathrm{C}-\mathrm{N}$ and $\mathrm{Si}-\mathrm{B}-\mathrm{C}-\mathrm{N}$ systems, ${ }^{107,108}$ nanoparticles or nanowires free or embedded in a polymer, glass, or ceramic matrix, organicinorganic nanocomposites, porous materials ranging from zeolites to metal organic frameworks, oxide multilayer films, and many more. An example of building new materials from exfoliated sheets is illustrated schematically in Fig. 7.

The challenge is to use available synthetic capabilities to make new materials in a sensible and systematic fashion and to explore the physical properties of such materials with an eye to unique behavior and novel applications. This brings the synthetic chemist and ceramist together, especially when complex organometallic precursors are used or when inorganic materials are functionalized with organic groups. Computation will play an important role in the process, and will likely expand to beyond density functional theory approaches ${ }^{12}$ to include genetic algorithms, ${ }^{109}$ data mining, and other statistical approaches. ${ }^{110}$ High-throughput experimentation will also be valuable for accelerated materials development. ${ }^{111}$

Low-dimensional materials, which have unique properties that cannot be achieved in bulk material (e.g., huge anisotropy, ballistic conductivity, etc.), are one example of the starting point for this type of research. ${ }^{105,112,113}$ The recent discovery of 2-D carbides and carbonitrides of transition metals opens a new avenue for research in low-dimensional ceramics, because commonly studied 2-D ceramics, such as clays and oxide/hydroxides, are all insulators, while the new materials, called MXenes, are electrically conductive. ${ }^{114,115}$ While exact properties and the best applications are still to be determined, the electrical and mechanical properties measured for the first representatives of this class of materials are promising. One challenge is to develop improved methods for the synthesis of 2-D carbides, nitrides, oxycarbides, carbofluorides and other compounds in bulk and as thin films (e.g., molecular beam epitaxy, chemical vapor deposition, electrochemical or chemical exfoliation of MAX phases, synthesis from graphene, etc.). Another challenge is to predict and experimentally measure the properties of 2-D ceramics. A final challenge is to integrate the 2-D ceramics into glass, ceramic, and other matrices, and to develop 3-D structures utilizing 2-D building blocks for a variety of applications.
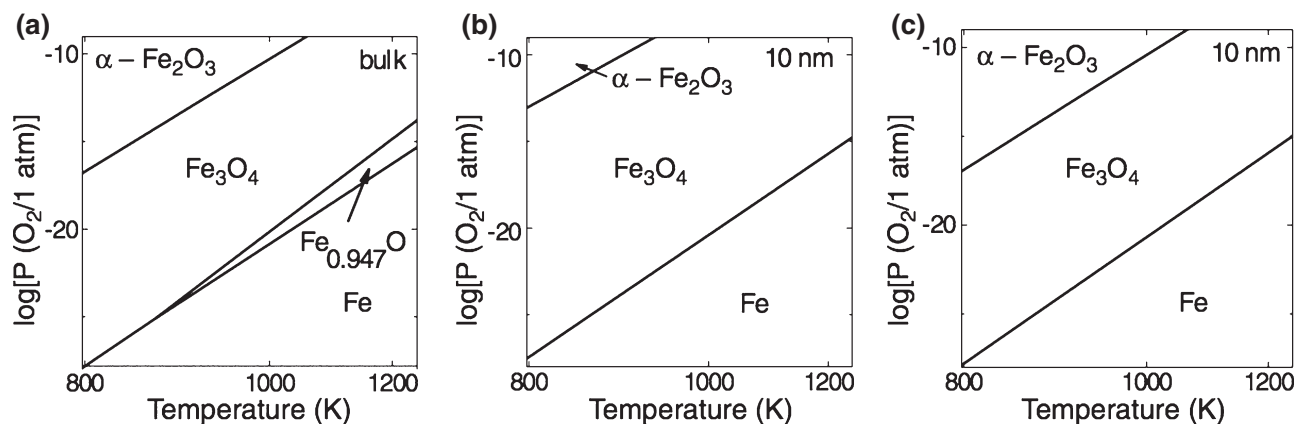

Fig. 6. Calculated phase diagram for bulk (a) and $10 \mathrm{~nm}$ spherical iron oxide particles in the (b) anhydrous and (c) hydrated state. For the $10 \mathrm{~nm}$ particles, wustite $\left(\mathrm{Fe}_{0.947} \mathrm{O}\right)$ is not a stable phase. Reproduced from Navrotsky et al. ${ }^{89}$ Copyright AAAS, reproduced with permission. 
(a) Flocculation

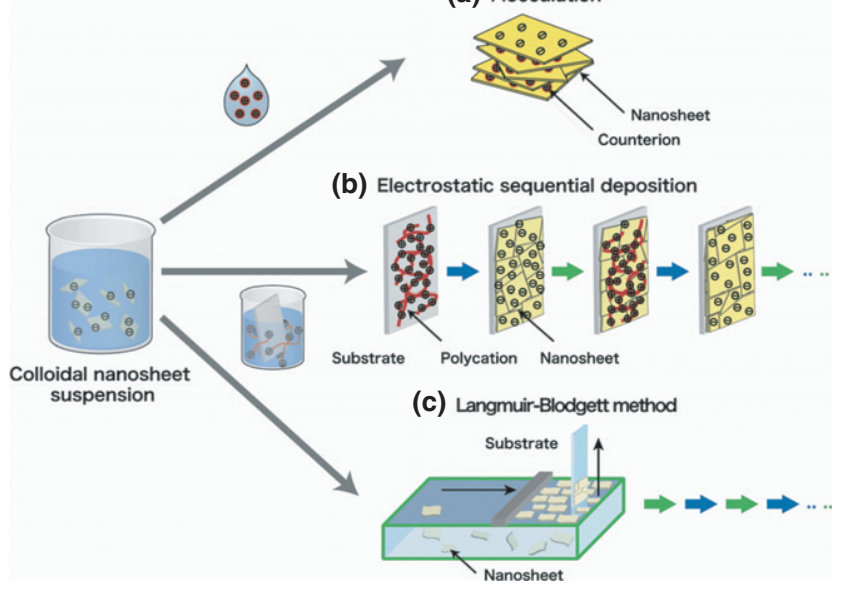

Fig. 7. A schematic illustrating ways to assemble exfoliated nanosheets into new solids. Figure reproduced from Ma and Sasaki. ${ }^{105}$ Copyright John Wiley and Sons, reproduced with permission.

The low-temperature, low-pressure synthesis of nonoxides that are traditionally processed at high temperatures and pressures is another example. One suitable route for such purposes is mechanochemical synthesis which makes it possible to form complex compounds by applying mechanical force to mixtures of elemental powders, involving repeated cold welding, fracturing, and rewelding of powder particles due to heavy deformation. ${ }^{116}$ During synthesis, the local frictional heating provides the required thermal energy to lower the activation barrier for synthesis. One of the examples of mechanochemical synthesis leading to a previously unreported ceramic structure is the synthesis of hexagonal osmium diboride $\left(\mathrm{OsB}_{2}\right) .{ }^{117}$

\section{(8) Harnessing Order Within Disorder in Glasses: Understanding and Control of the Intermediate-Range Order in Glasses to Enable Novel Properties}

Even though glass has been known since ancient civilizations, understanding and controlling the intermediate-range order (IRO) in glasses remains a grand challenge. Overcoming this challenge will lead to a breakthrough in tuning and processing bulk and surface (interface) glass structures, hence enabling the predictive design of glasses. Overcoming this challenge will lead to related benefits such as stronger glasses that last longer.

Highly disordered inorganic materials are of widespread importance in advanced technologies, for example, in oxide glasses used in flat screen displays, optical data transmission, and structural composites, and in multicomponent, defectrich crystalline solid solutions such as ion-conducting solid electrolytes in fuel cells or batteries. In many cases, the properties of such materials can be "tuned" by adjusting the composition over relatively wide ranges, or through modifying thermal history and other processing variables. However, this process often remains highly empirical, in part because of the difficult, general challenge of accurately quantifying the short - to intermediate - range structure of disordered materials to provide predictive structure-property relationships and/or to validate and develop theoretical models and simulations.

Structural tools such as diffraction methods that have revealed most of what we know about the structure of ordered crystals are of limited use for disordered solids and glass-forming liquids, providing only long-range average structure: 3-D in disordered crystals, only 1-D in amorphous materials. Spectroscopic methods, including vibrational, $\mathrm{X}$-ray and NMR, have been widely applied, and in some cases can provide highly quantitative details about some aspects of the structure, for example the populations of B, $\mathrm{Al}$, and $\mathrm{Si}$ cations with different coordination numbers in oxide glasses. ${ }^{118,119}$ However, in many cases there is much additional information in such spectra that cannot yet be quantified, bearing on the crucial question of how disordered the system is and how the disorder varies with composition and synthesis conditions. The missing link is often our limited ability to accurately go from a model of the disordered structure to a full, quantitative prediction of a spectrum. Developing such capability is a major computational and theoretical challenge whose resolution could vastly enhance our understanding of such materials. Such models need to contain large enough numbers of atoms to include the behavior of minor components (e.g., traces of $\mathrm{H}_{2} \mathrm{O}$ ), as well as the consequences of structural complexity arising from heterogeneity, hierarchical packing, and anisotropy (Fig. 8). Conversely, going from improved knowledge of the state of disorder to predictions of properties requires the development of models that treat the consequences for (a) degree of polymerization

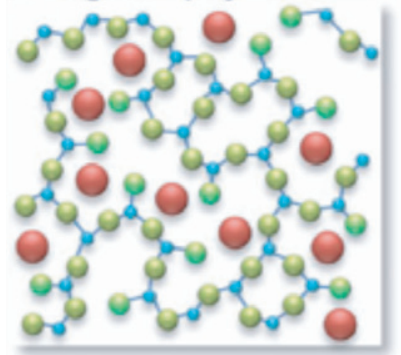

(d) packing denisity

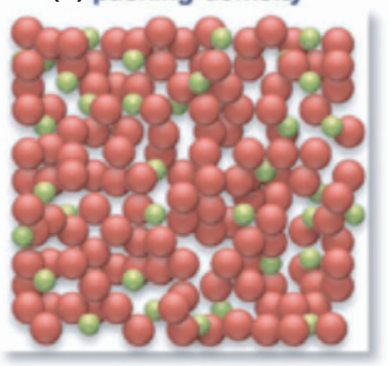

(b) channel formation

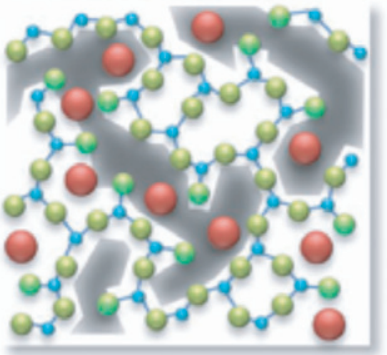

(e) formation of sub-lattices

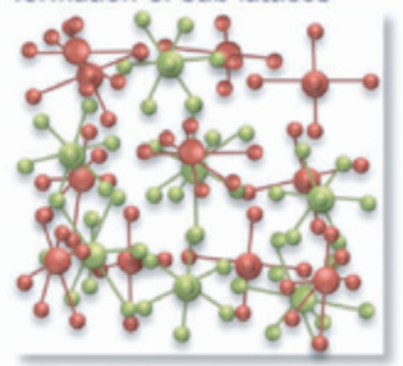

(c) structural dimensionality

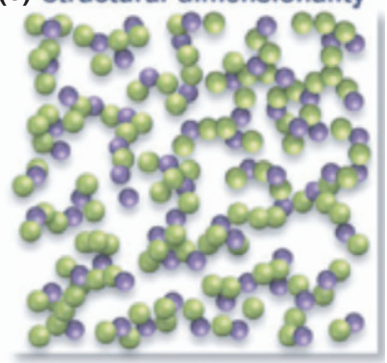

(f) interpenetrating networks

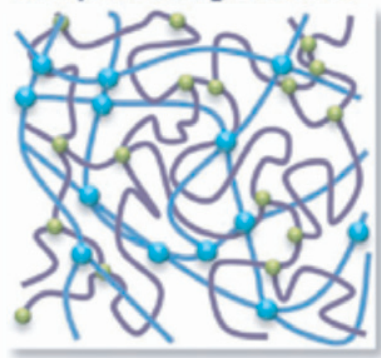

Fig. 8. Schematic types of design principles for the mesoscale structure in terms of heterogeneity, hierarchical packing, and anisotropy, and hence properties of glasses. ${ }^{127}$ Copyright John Wiley and Sons, reproduced with permission. 
thermodynamics and dynamics of the disorder. Examples include the role of configurational entropy in the viscosity of glass-forming liquids ${ }^{120,121}$ and in the free energies (and hence phase equilibria) of the liquids and corresponding disordered crystals.

Intermediate-range order, meaning nonrandom structure beyond the first two or three coordination shells, is a longstanding problem in glasses and glass-forming liquids. Its presence has implications not only for bulk structure and properties but also for diffusion and corrosion of glass surfaces, and thus for strength and fracture toughness.

The elucidation of IRO will have an immediate impact on the transport properties of many glass families. For example, the channel model for alkali silicates changes dramatically our approach to understanding the diffusion of ions into or out of the bulk (Fig. 9). While a number of models for such mesoscale structures have been proposed based on both experiment and computation, none have been validated or incorporated into multiscale models and simulations. Ion-conducting glasses, ${ }^{122}$ at the heart of novel solid state batteries, will be improved through a better understanding of conduction pathways in solid electrolytes and the role of Coulombic and strain effects. ${ }^{123}$ Similarly, detectors for medical and high-energy physics applications, especially resistive plate calorimeters ${ }^{124}$ in the latter, will be enhanced by better understanding the role of IRO in the DC hopping motion of electrons. Finally, the use of porous glasses as membranes in filter applications also depends on the role played by molecular structures in the mesoscale. ${ }^{125}$

On the other hand, the structure of glass surfaces (interfaces) remains widely unknown despite the fact that the functionality of such surfaces is widely used and that glass surfaces have played an important technical role as displays and interactive screens, as substrates for solar cells, for cell growth, etc. The surface of a glass as a frozen liquid is expected to be atomically smooth in its pristine state. However, even in vacuum, glass surfaces show atom rearrangement, migration of mobile ions to the surface and consequent roughening and nanostructure formation on the surface. In the presence of water or other reactive environments, such reactions are even more prevalent and often accompanied by water penetration into the glass surface. Of course, all of this occurs under the driving force of local chemical potential as well as the overall metastability of the glass and its surface relative to the hydrated or crystalline state. The mechanism and kinetics of these surface reactions is fundamentally dependent on the IRO that extends from the surface into the bulk of the glass structure. The

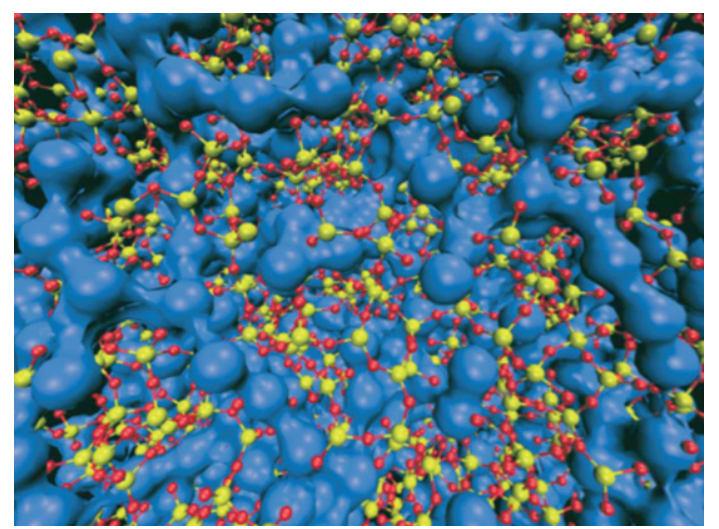

Fig. 9. Molecular dynamics snapshot of the structure of sodium trisilicate at $2100 \mathrm{~K}$ at the density $=2.2 \mathrm{~g} / \mathrm{cm}^{3}$ : The blue spheres that are connected to each other represent the $\mathrm{Na}$ atoms. The $\mathrm{Si}-\mathrm{O}$ network is drawn by yellow $(\mathrm{Si})$ and red $(\mathrm{O})$ spheres that are connected to each other by covalent bonds shown as sticks between $\mathrm{Si}$ and $\mathrm{O}$ spheres. ${ }^{146}$ Reprinted with permission from Reference 125. Copyright 2004 by the American Physical Society. mesoscale structure at the surface is needed to understand surface adsorption, surface segregation, surface diffusion, surface energy and wetting, ion exchange kinetics, distribution of applied or residual stress, and surface crystallization kinetics. Most notable is the potential effect of mesoscale structure on strength as the discontinuities in the network structure or internal interfaces which intersect the surface could constitute weak boundary layers and/or stress concentrators where cracks can nucleate, especially under the combined effects of stress and environmental attack (so-called stress corrosion). In this sense, the strength of pristine glass is determined by the surface structure and its chemical reaction with the environment, particularly with $\mathrm{H}_{2} \mathrm{O}$ (Fig. 10).

Glasses have been recognized as the intrinsically strongest man-made material, e.g., a tensile strength of up to $14 \mathrm{GPa}$ was demonstrated for silica glass drawn to fibers in vacuum. ${ }^{126}$ However, due to the weakness of the glass surface against both chemical (humidity) and mechanical (e.g., cracks, scratches, chips) aggression, we are far away from taking advantage of the exceptional mechanical properties of glass (the typical strength of glass is $\sim 50 \mathrm{MPa}$ ). Glass making is an energy intensive process. If we can tap the intrinsic strength of glass by increasing the practical strength by $50-100$ times, it will dramatically reduce the raw material consumption and the energy needs for the manufacture and transportation of glasses. This is one among many other benefits that stronger glasses can bring to us. Understanding and manipulation of IRO in the bulk and surface of glass is the key to tapping the intrinsic strength of glasses. Such a view is shared in a recent review paper ${ }^{127}$ and in a newly launched priority program in Germany on "Topological Engineering of Ultra-strong Glasses (SPP 1594)."

In addition to strength, an understanding of the surface mesoscale structure would impact other important properties and applications of glass, including chemical and mechanical durability, adhesion in polymer laminates and other composites, stability as a thin film substrate, tunability as a living cell or biochemical substrate, or precursor to a nanostructured optical or plasmonic surface/interface.

The electric field enhancement created at the surface of noble metal and semiconducting nanoparticles (a fine example is gold nanoparticles imparting the ruby color to glass in the famous Lycurgus Cup), ${ }^{128}$ and in the gaps and interstices of nanoparticle clusters, has been widely exploited for surface enhanced Raman spectroscopy and related "nanoplasmonic" phenomena. It is expected that oxide materials can have even higher carrier densities $\left(10^{13}-10^{14} \mathrm{~cm}^{-2}\right)$ than metal and semiconductor nanoparticles, although this has not yet been

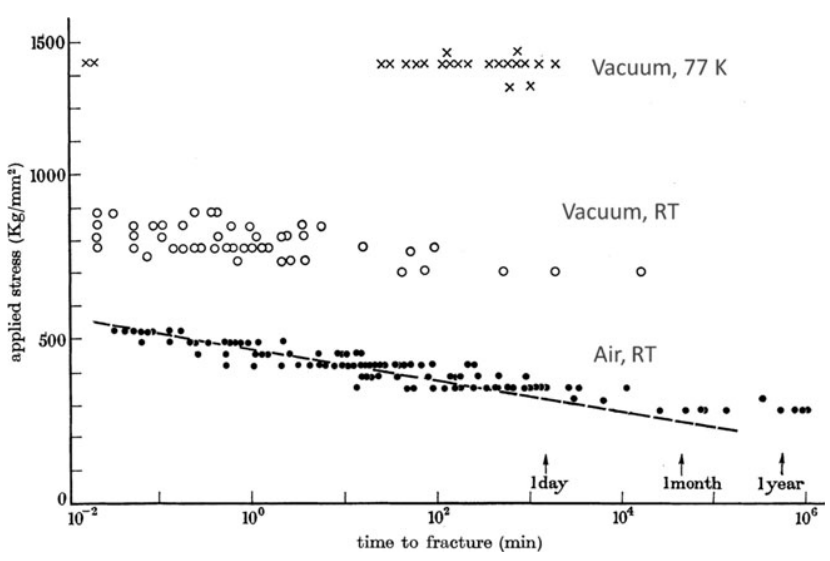

Fig. 10. Time dependence of tensile strength of silica fibers in vacuum at $77 \mathrm{~K}$ (filled triangles), in vacuum at room temperature (open circles), and in air at room temperature (filled circles). ${ }^{155}$ Copyright The Royal Society, reproduced with permission. 
widely exploited. Nanoparticle glasses (i.e., glasses containing metal, semiconductor, or semiconducting oxide nanoparticles) are poised to take advantage of nanoplasmoncs to create new nonlinear optics, luminescent and scintillation glasses for sensors and information technology. The progress already made in this field (largely theory and nanofabrication of plasmonic thin film devices) can now be combined with existing knowledge about crystallization in glasses to control the processing and properties of nanoparticle glasses to create a new class of optical and waveguide materials. ${ }^{129-131}$ The incorporation of heavy-metal oxide rare earth nanoparticles could be especially valuable for the next generation of scintillation detectors required for the Large Hadron Collider (http://www.lhc.ac.uk/).

Many disordered solids are far from their equilibrium states. One consequence is that the structure and properties can be especially dependent on the synthesis route, particularly on the thermal or energetic history of the synthesis process. ${ }^{132-134}$ The development of order on cooling or disorder on heating is inherently dynamic, and is often best studied by in situ, high temperature methods. Such experiments are often technically challenging and need further development; again, the even greater challenge can be going from spectra to accurate, quantitative pictures of the structure. Theoretical and computational developments could lead to major breakthroughs in interpreting such data and understanding fundamental dynamical processes. In situ structural measurements are also especially useful for testing/validating models (e.g., molecular dynamics), for which computational limits restrict the range of real temperatures that can be accurately simulated. $^{135}$

New techniques for experimental observation of IRO, such as multinuclear and multidimensional NMR methods that reveal correlations between structural environments of different cationic and anionic groups, ${ }^{136-140}$ will become increasingly important when coupled with more complete theoretical treatments. Experimental measurements that highlight surface structure, and/or structures that are proximal to such reactive species, are thus especially important. Deformation and damage to glass often involves local and high concentrations of stress. The response of the structure to stress is complexly dependent on composition, and is just beginning to be explored by studies of decompressed, densified materials. ${ }^{141}$ Again, in situ measurements that reveal the mechanical-chemical effects will be especially important. Recent advances in fluctuation electron microscopy, ${ }^{142}$ surfaceenhanced X-ray absorption fine structure at NSLSII (http:// www.bnl.gov/ps/nsls2/about-NSLS-II.asp), atomic force microscopy, ${ }^{143}$ spatially and spectrally resolved cathodoluminescence, ${ }^{144}$ etc., together with large-scale computer simulation and modeling of adsorption, diffusion, and reaction in glass ${ }^{145-151}$ under the influence of stress, and the availability of highquality thin drawn glass makes studies of mesoscale structure and its influence on glass properties within reach.

Experimental data accumulated over the past few decades, together with emerging in situ measurements, will provide the base for developing and validating the theory and model. Simulation will help explain experimental observations and clarify the range of validity of theory and model. Synergistic efforts among experiment, simulation, theory, and model will enable us to achieve the overall goals of the grand challenge in the next 5-10 yr.

\section{Summary}

The attendees of the workshop reached a consensus on eight grand challenges for ceramic science. For the most part, these challenges leverage new capabilities in materials characterization, synthesis, and modeling that open the door to measuring or simulating complex phenomena that were previously out of reach. The challenges are a mixture of long-standing problems, such as IRO in glass, and new opportunities such as the electronic properties of oxide heterostructures. These challenges provide a broad range of interesting directions for ceramic research over the next 5-10 yr.

\section{Acknowledgments}

The workshop and report were supported by National Science Foundation grant DMR-1216415. The authors thank Dr. Lynnette Madsen for encouragement and guidance during the planning and execution of this workshop.

\section{References}

${ }^{1}$ Y. M. Chiang and K. Jakus, "Fundamental Research Needs in Ceramics: Report from the 1997 NSF Workshop." Available at: http://www-unix.ecs. umass.edu/ jakus/nsf/nsf.ceramics.report6.pdf (accessed on 12 October 2012).

${ }^{2}$ K. Niihara, T. Ohji, and Y. Sakka, "3rd International Congress on Ceramics (ICC3)," IOP Conf. Ser., 18, 012001, 4 pp (2011).

${ }^{3}$ I. M. Robertson, C. A. Schuh, J. S. Vetrano, N. D. Browning, D. P. Field, D. J. Jensen, M. K. Miller, I. Baker, D. C. Dunand, R. Dunin-Borkowski, B. Kabius, T. Kelly, S. Lozano-Perez, A. Misra, G. S. Rohrer, A. D. Rollett, M. L. Taheri, G. B. Thompson, M. Uchic, X. L. Wang, and G. Was, "Towards an Integrated Materials Characterization Toolbox," J. Mater. Res., 26 [11] 1341-83 (2011)

${ }^{4}$ L. W. Martin, Y. H. Chu, and R. Ramesh, "Advances in the Growth and Characterization of Magnetic, Ferroelectric, and Multiferroic Oxide Thin Films," Mater. Sci. Eng., R, 68 [4-6] 111-333 (2010).

${ }^{5}$ J. E. Garay, "Current-Activated, Pressure-Assisted Densification of Materials"; pp. 445-68 in Annual Review of Materials Research, Vol. 40, Edited by D. R. Clarke, M. Ruhle, and F. Zok. Publisher Annual Reviews, Palo Alto, CA, 2010.

${ }_{6}^{6}$ J. A. Horn, S. C. Zhang, U. Selvaraj, G. L. Messing, and S. Trolier-McKinstry, "Templated Grain Growth of Textured Bismuth Titanate," J. Am. Ceram. Soc., 82 [4] 921-6 (1999).

${ }^{7}$ M. M. Seabaugh, I. H. Kerscht, and G. L. Messing, "Texture Development by Templated Grain Growth in Liquid-Phase-Sintered Alpha-Alumina," J. Am. Ceram. Soc., 80 [5] 1181-8 (1997)

${ }^{8}$ S. Jin, T. H. Tiefel, M. McCormack, R. A. Fastnacht, R. Ramesh, and L. H. Chen, "Thousandfold Change in Resistivity in Magnetoresistive La-CaMn-O Films," Science, 264 [5157] 413-5 (1994).

${ }^{9}$ A. Tsukazaki, A. Ohtomo, T. Kita, Y. Ohno, H. Ohno, and M. Kawasaki, "Quantum Hall Effect in Polar Oxide Heterostructures," Science, 315 [5817] 1388-91 (2007)

${ }^{10}$ S. J. Dillon, M. Tang, W. C. Carter, and M. P. Harmer, "Complexion: A New Concept for Kinetic Engineering in Materials Science," Acta Mater., 55 [18] 6208-18 (2007).

${ }^{1}$ S. Curtarolo, W. Setyawan, G. L. W. Hart, M. Jahnatek, R. V. Chepulskii, R. H. Taylor, S. D. Wanga, J. K. Xue, K. S. Yang, O. Levy, M. J. Mehl, H. T. Stokes, D. O. Demchenko, and D. Morgan, "AFLOW: An Automatic Framework for High-Throughput Materials Discovery," Comput. Mater. Sci. 58, 218-26 (2012).

${ }^{12}$ S. Wang, Z. Wang, W. Setyawan, N. Mingo, and S. Curtarolo, “Assessing the Thermoelectric Properties of Sintered Compounds via High-Throughput Ab-Initio Calculations," Phys. Rev. X, 1, 021012 (2011).

${ }^{13}$ R. Krishnamurthy, Y. G. Yoon, D. J. Srolovitz, and R. Car, "Oxygen Diffusion in Yttria-Stabilized Zirconia: A New Simulation Model," J. Am. Ceram. Soc., 87 [10] 1821-30 (2004).

${ }^{14}$ V. Tikare, M. Braginsky, D. Bouvard, and A. Vagnon, "Numerical Simulation of Microstructural Evolution During Sintering at the Mesoscale in a 3D Powder Compact," Comput. Mater. Sci., 48 [2] 317-25 (2010).

${ }^{15}$ S. A. Langer, E. Fuller, and W. C. Carter, "OOF: An Image-Based FiniteElement Analysis of Material Microstructures," Comp. Sci. Eng., 3 [3] 15-23 (2001).

${ }^{16}$ T. M. Pollock, J. E. Allison, D. G. Backman, M. C. Boyce, M. Gersh, E. A. Holm, R. LeSar, M. Long, A. C. Powell, J. J. Schirra, D. Demania Whitis, and C. Woodward, Integrated Computational Materials Engineering: A Transformational Discipline for Improved Competitiveness and National Security. National Academy of Sciences, Washington, DC, 2008.

17 "Materials Genome Initiative for Global Competitiveness." White House Office of Science Technology and Policy, 2011. Available at http://www. whitehouse.gov/sites/default/files/microsites/ostp/materials_genome_initiativefinal.pdf (accessed on 12 October 2012).

${ }^{18}$ W. Weibull, "A Statistical Distribution Function of Wide Applicability," J. Appl. Mech.-Trans. ASME, 18 [3] 293-7 (1951).

${ }^{19} \mathrm{H}$. Touchette, "A Basic Introduction to Large Deviations: Theory, Applications, Simulations"; pp. 1-51 in Modern Computational Science 11. Lecture Notes from the 3rd International Oldenburg Summer School, Edited by R. Leidl and A. K. Hartmann. Bis-verlag der Carl von Ossietzky Universität Oldenburg, Oldenburg, Germany, 2011.

${ }^{20}$ B. J. Harder, J. Almer, K. N. Lee, and K. T. Faber, "In Situ Stress Analysis of Multilayer Environmental Barrier Coatings," Powder Diffr., 24 [2] 94-8 (2009).

${ }^{21}$ G. N. Morscher, G. Ojard, R. Miller, Y. Gowayed, U. Santhosh, J. Ahmad, and R. John, "Tensile Creep and Fatigue of Sylramic-iBN Melt-Infiltrated SiC Matrix Composites: Retained Properties, Damage Development, and Failure Mechanisms," Compos. Sci. Technol., 68 [15-16] 3305-13 (2008).

${ }^{22}$ E. A. Marquis, N. A. Yahya, D. J. Larson, M. K. Miller, and R. I. Todd, "Probing the Improbable: Imaging C Atoms in Alumina," Mater. Today, 13 [10] 34-6 (2010). 
${ }^{23}$ K. J. Batenburg, S. Bals, J. Sijbers, C. Kubel, P. A. Midgley, J. C. Hernandez, U. Kaiser, E. R. Encina, E. A. Coronado, and G. Van Tendeloo, "3D Imaging of Nanomaterials by Discrete Tomography," Ultramicroscopy, 109 [6] 730-40 (2009).

${ }^{24}$ S. J. Dillon and G. S. Rohrer, "Characterization of the Grain-Boundary Character and Energy Distributions of Yttria Using Automated Serial Sectioning and EBSD in the FIB," J. Am. Ceram. Soc., 92 [7] 1580-5 (2009).

${ }^{25}$ A. Morales-Rodriguez, P. Reynaud, G. Fantozzi, J. Adrien, and E. Maire, "Porosity Analysis of Long-Fiber-Reinforced Ceramic Matrix Composites Using X-ray Tomography,” Scripta Mater., 60 [6] 388-90 (2009).

${ }^{26}$ M. Syha, W. Rheinheimer, M. Baurer, E. M. Lauridsen, W. Ludwig, D. Weygand, and P. Gumbsch, "Three-Dimensional Grain Structure of Sintered Bulk Strontium Titanate from X-Ray Diffraction Contrast Tomography," Scripta Mater., 66 [1] 1-4 (2012).

${ }^{27}$ G. A. Gonzons, J. W. McCauley, and I. G. Batyrev, "Multiscale Modeling of Armor Ceramics: Focus on AlON"; pp. 1-11 in ARL Tech Report, ARLRP-337. Army Research Laboratory, Aberdeen, MD, 2011.

${ }^{28}$ W. L. Ellsworth and G. C. Beroza, "Seismic Evidence for an Earthquake Nucleation Phase," Science, 268 [5212] 851-5 (1995).

${ }^{29}$ L. Borcea, G. Papanicolaou, C. Tsogka, and J. Berryman, "Imaging and Time Reversal in Random Media," Inverse Prob., 18 [5] 1247-79 (2002).

${ }^{30}$ C. H. Wang, J. T. Rose, and F. K. Chang, "A Synthetic Time-Reversal Imaging Method for Structural Health Monitoring," Smart Mater. Struct., 13 [2] 415-23 (2004).

${ }^{31}$ A. J. Allen, "Characterization of Ceramics by X-Ray and Neutron SmallAngle Scattering," J. Am. Ceram. Soc., 88 [6] 1367-81 (2005).

${ }^{32}$ M. D. Hager, P. Greil, C. Leyens, S. van der Zwaag, and U. S. Schubert, "Self-Healing Materials," Adv. Mater., 22 [47] 5424-30 (2010).

${ }^{33}$ J. Cho, C. M. Wang, H. M. Chan, J. M. Rickman, and M. P. Harmer, "Role of Segregating Dopants on the Improved Creep Resistance of Aluminum Oxide," Acta Mater., 47 [15-16] 4197-207 (1999).

${ }^{34}$ J. H. Cho, M. P. Harmer, H. M. Chan, J. M. Rickman, and A. M. Thompson, "Effect of Yttrium and Lanthanum on the Tensile Creep Behavior of Aluminum Oxide," J. Am. Ceram. Soc., 80 [4] 1013-7 (1997)

${ }^{35}$ S. Lartigue-Korinek, C. Carry, F. Dupau, and L. Priester, "Transmission Electron Microscopy Analysis of Grain Boundary Behavior in Superplastic Doped Alumina," Mater. Sci. Forum, 170-172, 409-14 (1994).

${ }^{36}$ K. Matsunaga, H. Nishimura, H. Muto, T. Yamamoto, and Y. Ikuhara, "Direct Measurements of Grain Boundary Sliding in Yttrium-Doped Alumina Bicrystals," Appl. Phys. Lett., 82 [8] 1179-81 (2003).

${ }^{37}$ H. Yoshida, Y. Ikuhara, and T. Sakuma, "Transient Creep in FineGrained Polycrystalline $\mathrm{Al}_{2} \mathrm{O}_{3}$ with $\mathrm{Lu}^{3+}$ Ion Segregation at the Grain Boundaries," J. Mater. Res., 16 [3] 716-20 (2001).

${ }^{38}$ H. Yoshida, A. Kuwabara, T. Yamamoto, Y. Ikuhara, and T. Sakuma, "High Temperature Plastic Flow and Grain Boundary Chemistry in Oxide Ceramics," J. Mater. Sci., 40 [12] 3129-35 (2005).

${ }^{39}$ K. Bedu-Amissah, J. M. Rickman, H. M. Chan, and M. P. Harmer, "Grain-Boundary Diffusion of $\mathrm{Cr}$ in Pure and Y-Doped Alumina," J. Am. Ceram. Soc., 90 [5] 1551-5 (2007).

${ }^{40}$ H. K. Cheng, S. J. Dillon, H. S. Caram, J. M. Rickman, H. M. Chan, and M. P. Harmer, "The Effect of Yttrium on Oxygen Grain-Boundary Transport in Polycrystalline Alumina Measured Using Ni Marker Particles," J. Am. Ceram. Soc., 91 [6] 2002-8 (2008).

${ }^{41}$ T. Matsudaira, M. Wada, T. Saitoh, and S. Kitaoka, "The Effect of Lutetium Dopant on Oxygen Permeability of Alumina Polycrystals Under Oxygen Potential Gradients at Ultra-High Temperatures," Acta Mater., 58 [5] 1544-53 (2010).

${ }^{42}$ T. Matsudaira, M. Wada, T. Saitoh, and S. Kitaoka, "Oxygen Permeability in Cation-Doped Polycrystalline Alumina Under Oxygen Potential Gradients at High Temperatures," Acta Mater., 59 [14] 5440-50 (2011).

${ }^{43}$ J. A. Nychka and D. R. Clarke, "Quantification of Aluminum Outward Diffusion During Oxidation of FeCrAl Alloys," Oxid. Met., 63 [5-6] 325-52 (2005).

${ }^{44}$ C. M. Wang, G. S. Cargill, M. P. Harmer, H. M. Chan, and J. Cho, "Atomic Structural Environment of Grain Boundary Segregated $\mathrm{Y}$ and $\mathrm{Zr}$ in Creep Resistant Alumina from EXAFS," Acta Mater., 47 [12] 3411-22 (1999).

${ }^{45} \mathrm{H}$. Yoshida, Y. Ikuhara, T Sakuma, M. Sakurai, and E. Matsubara, "X-ray Absorption Fine-Structure Study on the Fine Structure of Lutetium Segregated at Grain Boundaries in Fine-Grained Polycrystalline Alumina," Phil. Mag., 84 [9] 865-76 (2004).

${ }^{46} \mathrm{P}$. Kansuwan and J. M. Rickman, "Role of Segregating Impurities in Grain-Boundary Diffusion," J. Chem. Phys., 126 [9] 094707 (2007).

${ }^{47}$ H. Yoshida, Y. Ikuhara, and T. Sakuma, "Grain Boundary Electronic Structure Related to the High Temperature Creep Resistance in Polycrystalline $\mathrm{Al}_{2} \mathrm{O}_{3}, "$ Acta Mater., 50 [11] 2955-66 (2002).

${ }^{48} \mathrm{~A}$. H. Heuer, "Oxygen and Aluminum Diffusion in Alpha- $\mathrm{Al}_{2} \mathrm{O}_{3}$ : How Much Do We Really Understand?" J. Eur. Ceram. Soc., 28 [7] 1495-507 (2008).

${ }^{49}$ J. W. Jeong, J. H. Han, and D. Y. Kim, "Effect of Electric Field on the Migration of Grain Boundaries in Alumina," J. Am. Ceram. Soc., 83 [4] 915-8 (2000).

${ }^{50}$ H. R. Jin, S. H. Yoon, J. H. Lee, N. M. Hwang, D. Y. Kim, and J. H. Han, "Effect of External Electric Field on the Grain Growth of Barium Titanate in $\mathrm{N}_{2}$ Atmosphere," J. Mater. Sci., 16 [11-12] 749-52 (2005).

${ }^{51} \mathrm{H}$. Conrad, "Space Charge and Grain Boundary Energy in Zirconia (3YTZP)," J. Am. Ceram. Soc., 94 [11] 3641-2 (2011).

${ }^{2}$ H. Conrad and D. Yang, "Dependence of the Sintering Rate and Related Grain Size of Yttria-Stabilized Polycrystalline Zirconia (3Y-TZP) on the
Strength of an Applied De electric Field," Mat. Sci. Eng. A-Struct., 528 [2930] 8523-9 (2011).

${ }^{53}$ J. Langer, M. J. Hoffmann, and O. Guillon, "Electric Field-Assisted Sintering in Comparison with the Hot Pressing of Yttria-Stabilized Zirconia," J. Am. Ceram. Soc., 94 [1] 131-8 (2011).

${ }^{54}$ Z. J. Wang, J. E. Alaniz, W. Y. Jang, J. E. Garay, and C. Dames, "Thermal Conductivity of Nanocrystalline Silicon: Importance of Grain Size and Frequency-Dependent Mean Free Paths," Nano Lett., 11 [6] 2206-13 (2011).

${ }^{55}$ O. L. Krivanek, G. J. Corbin, N. Dellby, B. F. Elston, R. J. Keyse, M. F. Murfitt, C. S. Own, Z. S. Szilagyi, and J. W. Woodruff, "An Electron Microscope for the Aberration-Corrected Era," Ultramicroscopy, 108 [3] 17995 (2008).

${ }^{56}$ M. Lentzen, B. Jahnen, C. L. Jia, A. Thust, K. Tillmann, and K. Urban, "High-Resolution Imaging with an Aberration-Corrected Transmission Electron Microscope," Ultramicroscopy, 92 [3-4] 233-42 (2002).

${ }^{57}$ D. A. Muller, L. F. Kourkoutis, M. Murfitt, J. H. Song, H. Y. Hwang, J. Silcox, N. Dellby, and O. L. Krivanek, "Atomic-Scale Chemical Imaging of Composition and Bonding by Aberration-Corrected Microscopy," Science, 319 [5866] 1073-6 (2008)

${ }^{58}$ D. M. Saylor, A. Morawiec, and G. S. Rohrer, "Distribution and Energies of Grain Boundaries in Magnesia as a Function of Five Degrees of Freedom," J. Am. Ceram. Soc., 85 [12] 3081-3 (2002).

${ }^{59}$ D. M. Saylor, A. Morawiec, and G. S. Rohrer, "Distribution of Grain Boundaries in Magnesia as a Function of Five Macroscopic Parameters," Acta Mater., 51 [13] 3663-74 (2003).

${ }^{60}$ D. M. Saylor, A. Morawiec, and G. S. Rohrer, "The Relative Free Energies of Grain Boundaries in Magnesia as a Function of Five Macroscopic Parameters," Acta Mater., 51 [13] 3675-86 (2003).

${ }^{61}$ S. J. Dillon, H. Miller, M. P. Harmer, and G. S. Rohrer, "Grain Boundary Plane Distributions in Aluminas Evolving by Normal and Abnormal Grain Growth and Displaying Different Complexions," Int. J. Mater. Res., 101 [1] 50-6 (2010).

${ }^{62}$ S. J. Dillon and M. P. Harmer, "Multiple Grain Boundary Transitions in Ceramics: A Case Study of Alumina," Acta Mater., 55 [15] 5247-54 (2007).

${ }^{63}$ G. Harley, R. Yu, and L. C. De Jonghe, "Proton Transport Paths in Lanthanum Phosphate Electrolytes," Solid State Ionics, 178 [11-12] 769-73 (2007).

${ }^{64}$ M. F. Ashby, Materials Selection in Mechanical Design, 4th edition. Elsevier, Oxford, UK, 2010.

${ }^{65} \mathrm{~J}$. A. Elliott, "Novel Approaches to Multiscale Modelling in Materials Science," Int. Mater. Rev., 56 [4] 207-25 (2011).

${ }^{66}$ J. R. Wilson, W. Kobsiriphat, R. Mendoza, H. Y. Chen, J. M. Hiller, D J. Miller, K. Thornton, P. W. Voorhees, S. B. Adler, and S. A. Barnett, "Three-Dimensional Reconstruction of a Solid-Oxide Fuel-Cell Anode," Nat. Mater., 5 [7] 541-4 (2006).

${ }^{67}$ J. J. Williams, Z. Flom, A. A. Amell, N. Chawla, X. Xiao, and F. De Carlo, "Damage Evolution in $\mathrm{SiC}$ Particle Reinforced Al Alloy Matrix Composites by X-Ray Synchrotron Tomography," Acta Mater., 58 [18] 6194-205 (2010).

${ }^{68}$ M. D. Novak and F. W. Zok, "High-Temperature Materials Testing with Full-Field Strain Measurement: Experimental Design and Practice," Rev. Sci. Instrum., 82 [11] 115101 (2011).

${ }^{69}$ R. K. Bordia and G. W. Scherer, "On Constrained Sintering. 1. Constitutive Model for a Sintering Body," Acta Metall., 36 [9] 2393-7 (1988).

${ }^{70}$ R. K. Bordia, R. Z. Zuo, O. Guillon, S. M. Salamone, and J. Rodel, "Anisotropic Constitutive Laws for Sintering Bodies," Acta Mater., 54 [1] 111 -8 (2006).

${ }^{11}$ E. A. Olevsky, "Theory of Sintering: From Discrete to Continuum," Mater. Sci. Eng., R, 23 [2] 41-100 (1998).

${ }^{72}$ E. A. Olevsky, V. Tikare, and T. Garino, "Multi-Scale Study of Sintering: A Review," J. Am. Ceram. Soc., 89 [6] 1914-22 (2006)

${ }^{73}$ H. Itahara, W. S. Seo, S. Lee, H. Nozaki, T. Tani, and K. Koumoto, "The Formation Mechanism of a Textured Ceramic of Thermoelectric $\left[\mathrm{Ca}_{2} \mathrm{CoO}_{3}\right]_{0.62} \mathrm{CoO}_{2}$ on beta- $\mathrm{Co}(\mathrm{OH})_{2}$ Templates Through In Situ Topotactic Conversion," J. Am. Chem. Soc., 127 [17] 6367-73 (2005).

${ }^{74}$ T. Tani, "Crystalline-Oriented Piezoelectric Bulk Ceramics with a Perovskite-Type Structure," J. Korean Phys. Soc., 32, S1217-20 (1998).

${ }^{75}$ G. Evans, G. V. Duong, M. J. Ingleson, Z. L. Xu, J. T. A. Jones, Y. Z. Khimyak, J. B. Claridge, and M. J. Rosseinsky, "Chemical Bonding Assembly of Multifunctional Oxide Nanocomposites," Adv. Funct. Mater., 20 [2] 231-8 (2010).

${ }^{76}$ R. Mezzenga and J. Ruokolainen, "Nanocomposites Nanoparticles in the Right Place," Nat. Mater., 8 [12] 926-8 (2009).

${ }^{7}$ Y. Zhao, K. Thorkelsson, A. J. Mastroianni, T. Schilling, J. M. Luther, B. J. Rancatore, K. Matsunaga, H. Jinnai, Y. Wu, D. Poulsen, J. M. J. Frechet, A. P. Alivisatos, and T. Xu, "Small-Molecule-Directed Nanoparticle Assembly Towards Stimuli-Responsive Nanocomposites," Nat. Mater., 8 [12] 979-85 (2009).

${ }^{78} \mathrm{~A}$. Ohtomo and H. Y. Hwang, "A High-Mobility Electron Gas at the $\mathrm{LaAlO}_{3} / \mathrm{SrTiO}_{3}$ Heterointerface," Nature, 427 [6973] 423-6 (2004).

${ }^{79} \mathrm{~K}$. Szot, M. Rogala, W. Speier, Z. Klusek, A. Besmehn, and R. Waser, " $\mathrm{TiO}_{2}$ - A Prototypical Memristive Material," Nanotechnology, 22 [25] 254001 (2011).

${ }^{80}$ R. Waser, R. Dittmann, G. Staikov, and K. Szot, "Redox-Based Resistive Switching Memories - Nanoionic Mechanisms, Prospects, and Challenges," Adv. Mater., 21 [25-26] 2632-63 (2009).

${ }^{81}$ G. L. Cheng, P. F. Siles, F. Bi, C. Cen, D. F. Bogorin, C. W. Bark, C. M. Folkman, J. W. Park, C. B. Eom, G. Medeiros-Ribeiro, and J. Levy, "Sketched Oxide Single-Electron Transistor," Nat. Nanotechnol., 6 [6] 343-7 (2011).

${ }^{82} \mathrm{~J}$. Mannhart and D. G. Schlom, "Oxide Interfaces - An Opportunity for Electronics," Science, 327 [5973] 1607-11 (2010). 
${ }^{83}$ C. H. Ahn, J. M. Triscone, and J. Mannhart, "Electric Field Effect in Correlated Oxide Systems," Nature, 424 [6952] 1015-8 (2003).

${ }^{84}$ J. Levy, "Oxide - Semiconductor Materials for Quantum Computation," Phys. Status Solidi B, 233 [3] 467-71 (2002).

${ }^{85}$ J. W. Fergus, "Electrolytes for Solid Oxide Fuel Cells," J. Power Sources, 162 [1] 30-40 (2006)

${ }^{86}$ G. J. Snyder and E. S. Toberer, "Complex Thermoelectric Materials," Nat. Mater., 7 [2] 105-14 (2008).

${ }^{87}$ E. D. Wachsman, C. A. Marlowe, and K. T. Lee, "Role of Solid Oxide Fuel Cells in a Balanced Energy Strategy," Energy Environ. Sci., 5 [2] 5498509 (2012).

${ }^{88}$ S. B. Adler, "Factors Governing Oxygen Reduction in Solid Oxide Fuel Cell Cathodes," Chem. Rev., 104 [10] 4791-843 (2004)

${ }^{89}$ A. Navrotsky, C. C. Ma, K. Lilova, and N. Birkner, "Nanophase Transition Metal Oxides Show Large Thermodynamically Driven Shifts in Oxidation-Reduction Equilibria," Science, 330 [6001] 199-201 (2010).

${ }^{90}$ L. Li, G. S. Rohrer, and P. A. Salvador, "Heterostructured Ceramic Powders for Photocatalytic Hydrogen Production: Nanostructured $\mathrm{TiO}_{2}$ Shells Surrounding Microcrystalline (Ba,Sr)TiO 3 Cores," J. Am. Ceram. Soc., 95 [4] 1414-20 (2012).

${ }^{91}$ Y. L. Zhang, A. M. Schultz, P. A. Salvador, and G. S. Rohrer, "Spatially Selective Visible Light Photocatalytic Activity of $\mathrm{TiO}_{2} / \mathrm{BiFeO}_{3}$ Heterostructures," J. Mater. Chem., 21 [12] 4168-74 (2011).

${ }^{92}$ J. Maier, "Nanoionics: Ion Transport and Electrochemical Storage in Confined Systems," Nat. Mater., 4 [11] 805-15 (2005).

${ }^{93}$ N. Sata, K. Eberman, K. Eberl, and J. Maier, "Mesoscopic Fast Ion Conduction in Nanometre-Scale Planar Heterostructures," Nature, 408 [6815] 946-9 (2000).

${ }^{94}$ J. Garcia-Barriocanal, A. Rivera-Calzada, M. Varela, Z. Sefrioui, E. Iborra, C. Leon, S. J. Pennycook, and J. Santamaria, "Colossal Ionic Conductivity at Interfaces of Epitaxial $\mathrm{ZrO}_{2}: \mathrm{Y}_{2} \mathrm{O}_{3} / \mathrm{SrTiO}_{3}$ Heterostructures," Science, 321 [5889] 676-80 (2008).

${ }^{95} \mathrm{H} . \mathrm{T} . \mathrm{Yi}, \mathrm{T}$. Choi, S. G. Choi, Y S. Oh, and S. W. Cheong, "Mechanism of the Switchable Photovoltaic Effect in Ferroelectric $\mathrm{BiFeO}_{3}$, " Adv. Mater., 23 [30] 3403-7 (2011).

${ }^{96}$ W. Jiang, M. Noman, Y. M. Lu, J. A. Bain, P. A. Salvador, and M. Skowronski, "Mobility of Oxygen Vacancy in $\mathrm{SrTiO}_{3}$ and its Implications for Oxygen-Migration-Based Resistance Switching," J. Appl. Phys., 110 [3] 034509 (2011).

${ }^{97}$ A. K. Tagantsev, E. Courtens, and L. Arzel, "Prediction of a Low-Temperature Ferroelectric Instability in Antiphase Domain Boundaries of Strontium Titanate," Phys. Rev. B, 64 [22] 224107 (2001).

${ }^{98}$ B. W. Sheldon and V. B. Shenoy, "Space Charge Induced Surface Stresses: Implications in Ceria and Other ionic Solids," Phys. Rev. Lett., 106 [21] 216104 (2011).

${ }^{99}$ F. A. Kroger and H. J. Vink, "Relations Between the Concentrations of Imperfections in Crystalline Solids," Solid State Phys. Adv. Res. Appl., 3, 307435 (1956).

${ }^{100}$ F. A. Kroger and H. J. Vink, "Relations Between the Concentrations of Imperfections in Solids,” J. Phys. Chem. Solids, 5 [3] 208-23 (1958).

${ }^{101}$ G. C. C. Costa, S. V. Ushakov, R. H. R. Castro, A. Navrotsky, and R. Muccillo, "Calorimetric Measurement of Surface and Interface Enthalpies of Yttria-Stabilized Zirconia (YSZ)," Chem. Mater., 22 [9] 2937-45 (2010).

${ }^{102}$ A. Navrotsky, "Nanoscale Effects on Thermodynamics and Phase Equilibria in Oxide Systems," ChemPhysChem, 12 [12] 2207-15 (2011).

${ }^{103}$ A. Navrotsky, L. Mazeina, and J. Majzlan, "Size-Driven Structural and Thermodynamic Complexity in Iron Oxides," Science, 319 [5870] 1635-8 (2008)

${ }^{104}$ G. S. Rohrer, "Grain Boundary Energy Anisotropy: A Review," $J$. Mater. Sci., 46 [18] 5881-95 (2011).

${ }^{105}$ R. Ma and T. Sasaki, "Nanosheets of Oxides and Hydroxides: Ultimate 2D Charge-Bearing Functional Crystallites," Adv. Mater., 22 [45] 5082-104 (2010).

${ }^{106}$ J. Reed and G. Ceder, "Role of Electronic Structure in the Susceptibility of Metastable Transition-Metal Oxide Structures to Transformation," Chem. Rev., 104 [10] 4513-33 (2004).

${ }^{107}$ R. M. Morcos, G. Mera, A. Navrotsky, T. Varga, R. Riedel, F. Poli, and K. Muller, "Enthalpy of Formation of Carbon-Rich Polymer-Derived Amorphous SiCN Ceramics," J. Am. Ceram. Soc., 91 [10] 3349-54 (2008).

${ }^{108}$ T. Varga, A. Navrotsky, J. L. Moats, R. M. Morcos, F. Poli, K. Muller, A. Sahay, and R. Raj, "Thermodynamically Stable Sixoycz Polymer-Like Amorphous Ceramics," J. Am. Ceram. Soc., 90 [10] 3213-9 (2007).

${ }^{109}$ N. Chakraborti, "Genetic Algorithms in Materials Design and Processing," Int. Mater. Rev., 49 [3-4] 246-60 (2004).

${ }^{110} \mathrm{P}$. V. Balachandran, S. R. Broderick, and K. Rajan, "Identifying the 'Inorganic Gene' for High-Temperature Piezoelectric Perovskites Through Statistical Learning," Proc. R. Soc. A Math. Phys. Eng. Sci., 467 [2132] 2271-90 (2011).

${ }^{111}$ R. Potyrailo, K. Rajan, K. Stoewe, I. Takeuchi, B. Chisholm, and H. Lam, "Combinatorial and High-Throughput Screening of Materials Libraries: Review of State of the Art," ACS Comb. Sci., 13 [6] 579-633 (2011).

${ }^{112}$ J. N. Coleman, M. Lotya, A. O’Neill, S. D. Bergin, P. J. King, U. Khan, K. Young, A. Gaucher, S. De, R. J. Smith, I. V. Shvets, S. K. Arora, G. Stanton, H.-Y. Kim, K. Lee, G. T. Kim, G. S. Duesberg, T. Hallam, J. J. Boland, J. J. Wang, J. F. Donegan, J. C. Grunlan, G. Moriarty, A. Shmeliov, R. J. Nicholls, J. M. Perkins, E. M. Grieveson, K. Theuwissen, D. W. McComb, P. D. Nellist, and V. Nicolosi, "Two-Dimensional Nanosheets Produced by Liquid Exfoliation of Layered Materials," Science, 331 [6017] 568-71 (2011).
${ }^{113}$ D. Pacile, J. C. Meyer, C. O. Girit, and A. Zettl, "The Two-Dimensional Phase of Boron Nitride: Few-Atomic-Layer Sheets and Suspended Membranes," Appl. Phys. Lett., 92 [13] 133107 (2008).

${ }^{14}$ M. Naguib, M. Kurtoglu, V. Presser, J. Lu, J. J. Niu, M. Heon, L. Hultman, Y. Gogotsi, and M. W. Barsoum, "Two-Dimensional Nanocrystals Produced by Exfoliation of $\mathrm{Ti}_{3} \mathrm{AlC}_{2}$, , Adv. Mater., 23 [37] 4248-53 (2011).

${ }^{115}$ M. Naguib, O. Mashtalir, J. Carle, V. Presser, J. Lu, L. Hultman, Y. Gogotsi, and M. W. Barsoum, "Two-Dimensional Transition Metal Carbides," ACS Nano, 6 [2] 1322-31 (2012).

${ }^{116}$ N. Orlovskaya, Z. L. Xie, M. Klimov, H. Heinrich, D. Restrepo, R. Blair, and C. Suryanarayana, "Mechanochemical Synthesis of ReB 2 Powder," J. Mater. Res., 26 [21] 2772-9 (2011)

${ }^{117}$ Z. Xie, N. Orlovskaya, D. A. Cullen, D. T. Restrepo, and R. G. Blair, "Mechanochemical Synthesis of Hexagonal $\mathrm{OsB}_{2}$, , Manuscript in preparation (2012).

${ }^{118}$ H. Eckert, "Structural Characterization of Noncrystalline Solids and Glasses Using Solid-State NMR,” Prog. Nucl. Magn. Reson. Spectrosc., 24, 159-293 (1992)

${ }^{19}$ J. F. Stebbins, “ NMR Studies of Oxide Glass Structure”; pp. 391-436 in Solid State NMR: Theory and Applications, Edited by M. Duer. Blackwell Scientific, Oxford, 2002

${ }^{120} \mathrm{P}$. Richet, M. A. Bouhifd, P. Courtial, and C. Tequi, "Configurational Heat Capacity and Entropy of Borosilicate Melts," J. Non-Cryst. Solids, 211 [3] 271-80 (1997).

${ }^{12}$ J. C. Mauro, Y. Z. Yue, A. J. Ellison, P. K. Gupta, and D. C. Allan, "Viscosity of Glass-Forming Liquids," Proc. Natl Acad. Sci. USA, 106 [47] 19780-4 (2009).

${ }^{122}$ A. Pradel and M. Ribes, "Ionic Conductive Glasses," Mater. Sci. Eng. B Solid State Mater. Adv. Technol., 3 [1-2] 45-56 (1989).

${ }^{123}$ Q. Mei, B. Meyer, D. Martin, and S. W. Martin, "Ion Trapping Model and the Non-Arrhenius Ionic Conductivity in Fast Ion Conducting Glasses," Solid State Ionics, 168 [1-2] 75-85 (2004)

${ }^{124}$ M. Bedjidian, K. Belkadhi, V. Boudry, C. Combaret, D. Decotigny, E. C. Gil, C. Taille, R. de la Dellanegra, V. A. Gapienko, G. Grenier, C. Jauffret, R. Kieffer, M. C. Fouz, R. Han, I. Laktineh, N. Lumb, K. Manai, S. Mannai, H. Mathez, L. Mirabito, J. P. Pelayo, M. Ruan, F. Schirra, N. SeguinMoreau, W. Tromeur, M. Tytgat, M. Vander Donckt, and N. Zaganidis, "Performance of Glass Resistive Plate Chambers for a High-Granularity Semi-Digital Calorimeter," J. Instrum., 6, P02001 (2011).

${ }^{125}$ M. I. Ryshchenko, L. A. Mikheenko, L. P. Shchukina, and A. A. Baturin, "Integrated Study of Phase Composition and Structure of Porous Glass Ceramics," Glass Ceram., 60 [5-6] 168-70 (2003).

${ }^{126}$ C. R. Kurkjian, P. K. Gupta, R. K. Brow, and N. Lower, "The Intrinsic Strength and Fatigue of Oxide Glasses," J. Non-Cryst. Solids, 316 [1] 114-24 (2003).

${ }^{127}$ L. Wondraczek, J. C. Mauro, J. Eckert, U. Kuhn, J. Horbach, J. Deubener, and T. Rouxel, "Towards Ultrastrong Glasses," Adv. Mater., 23 [39] 4578-86 (2011)

${ }^{128}$ F. E. Wagner, S. Haslbeck, L. Stievano, S. Calogero, Q. A. Pankhurst, and P. Martinek, "Before Striking Gold in Gold-Ruby Glass," Nature, 407 [6805] 691-2 (2000).

${ }^{129}$ A. N. MacDonald, A. Hryciw, Q. Li, and A. Meldrum, "Luminescence of Nd-Enriched Silicon Nanoparticle Glasses," Opt. Mater., 28 [6-7] 820-4 (2006).

${ }^{130}$ Z. L. Samson, S. C. Yen, K. F. MacDonald, K. Knight, S. F. Li, D. W. Hewak, D. P. Tsai, and N. I. Zheludev, "Chalcogenide Glasses in Active Plasmonics," Phys. Status Sol. RRL, 4 [10] 274-6 (2010).

${ }^{131}$ K. Hiromatsu, D. J. Hwang, and C. P. Grigoropoulos, "Active Glass Nanoparticles by Ultrafast Laser Pulses," Micro Nano Lett., 3 [4] 121-4 (2008).

${ }^{132}$ F. Angeli, O. Villain, S. Schuller, T. Charpentier, D. de Ligny, L. Bressel, and L. Wondraczek, "Effect of Temperature and Thermal History on Borosilicate Glass Structure," Phys. Rev. B, 85 [5] 054110 (2012).

${ }^{133}$ J. S. Wu and J. F. Stebbins, "Quench Rate and Temperature Effects on Boron Coordination in Aluminoborosilicate Melts," J. Non-Cryst. Solids, 356 [41-42] 2097-108 (2010).

${ }^{134}$ J. F. Stebbins, E. V. Dubinsky, K. Kanehashi, and K. E. Kelsey, "Temperature Effects on Non-Bridging Oxygen and Aluminum Coordination Number in Calcium Aluminosilicate Glasses and Melts," Geochim. Cosmochim. Acta, 72 [3] 910-25 (2008).

${ }^{135}$ K. Kanehashi and J. F. Stebbins, "In Situ High Temperature ${ }^{27}$ Al NMR Study of Structure and Dynamics in a Calcium Aluminosilicate Glass and Melt," J. Non-Cryst. Solids, 353 [44-46] 4001-10 (2007).

${ }^{136}$ F. Angeli, O. Villain, S. Schuller, S. Ispas, and T. Charpentier, "Insight into Sodium Silicate Glass Structural Organization by Multinuclear NMR Combined with First-Principles Calculations," Geochim. Cosmochim. Acta, 75 [9] 2453-69 (2011).

${ }^{37}$ L. S. Du and J. F. Stebbins, "Network Connectivity in Aluminoborosilicate Glasses: A High-Resolution ${ }^{11} \mathrm{~B},{ }^{27} \mathrm{Al}$ and ${ }^{17} \mathrm{O}$ NMR Study," J. NonCryst. Solids, 351[43-45] 3508-20 (2005).

${ }^{138}$ M. Bertmer, L. Zuchner, J. C. C. Chan, and H. Eckert, "Short and Medium Range Order in Sodium Aluminoborate Glasses. 2. Site Connectivities and Cation Distributions Studied by Rotational Echo Double Resonance NMR Spectroscopy," J. Phys. Chem. B, 104 [28] 6541-53 (2000).

${ }^{139}$ J. D. Epping, W. Strojek, and H. Eckert, "Cation Environments and Spatial Distribution in $\mathrm{Na}_{2} \mathrm{O}-\mathrm{B}_{2} \mathrm{O}_{3}$ glasses: New Results from Solid State NMR,' Phys. Chem. Chem. Phys., 7 [11] 2384-9 (2005).

${ }^{140}$ L. Zhang and H. Eckert, "Short- and Medium-Range Order in Sodium Aluminophosphate Glasses: New Insights from High-Resolution Dipolar Solid-State NMR Spectroscopy,” J. Phys. Chem. B, 110 [18] 8946-58 (2006). 
${ }^{141}$ J. S. Wu, J. Deubener, J. F. Stebbins, L. Grygarova, H. Behrens, L. Wondraczek, and Y. Z. Yue, "Structural Response of a Highly Viscous Aluminoborosilicate Melt to Isotropic and Anisotropic Compressions," J. Chem. Phys., 131 [10] 104504 (2009).

${ }^{142}$ P. M. Voyles, J. M. Gibson, and M. M. J. Treacy, "Fluctuation Microscopy: A Probe of Atomic Correlations in Disordered Materials," J. Electron Microsc., 49 [2] 259-66 (2000).

${ }^{143}$ F. Celarie, M. Ciccotti, and C. Marliere, "Stress-Enhanced Ion Diffusion at the Vicinity of a Crack Tip as Evidenced by Atomic Force Microscopy in Silicate Glasses," J. Non-Cryst. Solids, 353 [1] 51-68 (2007).

${ }^{144}$ G. Pezzotti and A. Leto, "Contribution of Spatially and Spectrally Resolved Cathodoluminescence to Study Crack-Tip Phenomena in Silica Glass," Phys. Rev. Lett., 103 [17] 175501 (2009).

${ }^{145}$ E. A. Leed and C. G. Pantano, "Computer Modeling of Water Adsorption on Silica and Silicate Glass Fracture Surfaces," J. Non-Cryst. Solids, 325 [1-3] 48-60 (2003).

${ }^{46}$ A. Meyer, J. Horbach, W. Kob, F. Kargl, and H. Schober, "Channel Formation and Intermediate Range Order in Sodium Silicate Melts and Glasses," Phys. Rev. Lett., 93 [2] 027801 (2004).

${ }^{147}$ J. C. Du and A. N. Cormack, "Molecular Dynamics Simulation of the Structure and Hydroxylation of Silica Glass Surfaces," J. Am. Ceram. Soc., 88 [9] 2532-9 (2005).
${ }^{148}$ E. R. Cruz-Chu, A. Aksimentiev, and K. Schulten, "Water-Silica Force field for Simulating Nanodevices," J. Phys. Chem. B, 110 [43] 21497-508 (2006).

${ }^{149}$ A. A. Hassanali and S. J. Singer, "Model for the Water-Amorphous Silica Interface: The Undissociated Surface," J. Phys. Chem. B, 111 [38] 11181 -93 (2007).

${ }^{150}$ T. S. Mahadevan and S. H. Garofalini, "Dissociative Chemisorption of Water onto Silica Surfaces and Formation of Hydronium Ions,"J. Phys. Chem. C, 112 [5] 1507-15 (2008).

${ }^{151}$ J. C. Fogarty, H. M. Aktulga, A. Y. Grama, A. C. T. van Duin, and S. A. Pandit, "A Reactive Molecular Dynamics Simulation of the Silica-Water Interface," J. Chem. Phys., 132 [17] 174704 (2010).

${ }^{152}$ L. Helmick, S. J. Dillon, K. Gerdes, R. Gemmen, G. S. Rohrer, S. Seetharaman, and P. A. Salvador, "Crystallographic Characteristics of Grain Boundaries in Dense Yttria-Stabilized Zirconia," Int. J. Appl. Ceram. Technol., 8 [5] 1218-28 (2011).

${ }^{153} \mathrm{G}$. S. Rohrer, "Measuring and Interpreting the Structure of Grain-Boundary Networks," J. Am. Ceram. Soc., 94 [3] 633-46 (2011).

${ }^{154}$ S. J. Dillon, M. P. Harmer, and G. S. Rohrer, "The Relative Energies of Normally and Abnormally Growing Grain Boundaries in Alumina Displaying Different Complexions," J. Am. Ceram. Soc., 93 [6] 1796-802 (2010).

${ }^{155}$ B. A. Proctor, I. Whitney, and J. W. Johnson, "Strength of Fused Silica," Proc. R. Soc. Lond. Ser. A Math. Phys. Sci., 297 [1451] 534-57 (1967). 